\title{
Molecular structure and modeling studies of azobenzene derivatives containing maleimide groups
}

\author{
Corneliu Cojocaru, Anton Airinei ${ }^{*}$ and Nicusor Fifere
}

\begin{abstract}
The molecular orbital calculations have been carried out to investigate the structure and stability of (E) / (Z) isomers of some azobenzene derivatives containing maleimide groups. A special attention has been devoted to the compound (E)-1, (E)-1-(4-(phenyldiazenyl)phenyl)-1H-pyrrole-2,5-dione, for which the available crystallographic experimental data have been used to validate the modeling structures computed at the theoretical levels AM1, $P M 3, R H F / 6-31+G(d, p)$ and B3LYP/6-31+G(d,p). To this end, the discrepancy between experimental and calculated structural parameters has been ascertained in terms of root-mean-square deviation (RMSD). The quantum calculations at the level RHF/6-31+G(d,p) yield the most accurate results on (E)-1 structure giving a deviation error from crystallographic data of about 5.00\% for bond lengths and $0.97 \%$ for interatomic angles. The theoretical electronic absorption spectra of azobenzene derivatives of concern have been computed by means of configuration-interaction method $(\mathrm{Cl})$ at the level of semi-empirical Hamiltonians (AM1 and PM3). Likewise, the molecular energy spectra, electrostatic potential and some quantitative structure activity relationship (QSAR) properties of studied molecules have been computed and discussed in the paper.
\end{abstract}

Keywords: Azobenzene derivatives; Isomers; Molecular orbital calculations; Electronic absorption spectra; HOMO-LUMO

\section{Introduction}

Azobenzene derivatives are molecularly versatile materials capable to provide a response to external stimuli, which allow the control of their photophysical properties. Due to their unique (E) / ( $\mathrm{Z}) /(\mathrm{E})$ isomerization process, the azobenzene derivatives found a wide applicability in many fields such as photoresponsive materials, optical data storage, surface relief gratings, optoelectronics switches, molecular machines, liquid crystal displays, etc. (Rau 1990a; Kumar \& Neckers 1989; Bouas-Laurent \& Durr 2001; Natansohn \& Rochon 2002; Angiolini et al. 2011; Ebead 2011; Fayet et al. 2010; Hamelmann et al. 2004; Matczyszyn et al. 2003; Kay et al. 2007; Merino \& Ribagorda 2012; Wang \& Zhang 2012; Delaire \& Nakatani 2000; Luftor et al. 2009; Ishow et al. 2006).

It is worth noting that one of the most intriguing aspects of azobenzene compounds is the photo-isomerization of $(\mathrm{E})$ and $(\mathrm{Z})$ isomers and their recovery to the starting $(\mathrm{E})$

\footnotetext{
*Correspondence: airineia@icmpp.ro

* Correspondence: airineia@icmpp.ro
"Petru Poni" Institute of Macromolecular Chemistry, Aleea Grigore Ghica Voda 41A, 700487 lasi, Romania
}

\section{Springer}

isomer. Knowledge of the structure of azobenzene derivative conformers is essential for the understanding the (E) / ( Z) / (E) isomerization mechanism (Shaabani \& Zahedi 2000; Kurita et al. 2002; Rau 1990b; Diau 2004; Schultz et al. 2003; Satzger et al. 2003; Airinei et al. 2010). It is well-known that the azobenzene compounds exhibit two absorption bands, an intense band located in the UV spectral region assigned to $\pi \rightarrow \pi^{*}$ and a weak band which can be found in the visible region assigned to $n \rightarrow \pi$ " electronic transition. Upon UV light $(365 \mathrm{~nm})$ irradiation, the energetically more stable (E) isomer can be converted to the non-planar $(\mathrm{Z})$ isomer. The $(\mathrm{Z}) /(\mathrm{E})$ backward isomerization process proceeds thermally or with blue light irradiation. The reversible $(\mathrm{Z})$ / $(\mathrm{E})$ photoisomerization of azobenzene moiety represents generally the basis for obtaining azobenzene-based photoresponsive materials (Bouas-Laurent \& Durr 2001; Natansohn \& Rochon 2002; Rau 1990b; Yager \& Barett 2006). Since the applications require the design of the specific azobenzene derivatives with given spectroscopic or photochromic characteristics, the theoretical calculations play an important role for 
revealing new structures and properties beside the traditional synthesis procedures.

Morley and co-workers (Morley et al. 2004) performed the molecular modeling studies on the photochemical stability of some azobenzene derivatives. The structure and electronic properties of a series of colored azobenzenes containing electron donors and attractors were calculated with both semi-empirical (AM1, PM3) and ab-initio methods. A good agreement was found between the predicted positions of the first and second absorption bands of the azo dyes calculated with AM1/ multi-electron configuration interaction method and the experimental values determined in methanol.

A detailed MNDO, AM1 and PM3 study on the stability of isomers of some p,p'-substituted azobenzene derivatives was reported (Shaabani \& Zahedi 2000). The results of their computations showed that according to MNDO and PM3 Hamiltonians (E) isomer was the most stable being in agreement with experimental results. However AM1 method suggests that $(Z)$ isomer was more stable, contrary to all experimental data.

Matsuura and collaborators (Matsuura et al. 2008) estimated the absorption maxima of some azobenzene derivatives using the AM1, PM3 and PM5 semi-empirical molecular orbital methods with the configuration interaction singles and random phase approximation calculations. These authors found out that absorption maxima determined by semi-empirical methods were in good correlations with the observed counterpart values.

In this work, semi-empirical methods (AM1 and PM3) have been employed as basic models to study theoretically some azobenzene derivatives containing maleimide moieties and to compare the modeling results with the available experimental data. The ground state and excited state, as well as their electronic structures and optical properties are discussed.

\section{Methodology \\ Modeled compounds}

The chemical structures of azobenzene derivatives considered for molecular modeling are shown in the Figure 1. Thus, four compounds (1-4) have been considered for modeling, and each one involves two isomers (E) and (Z). The titles of these compounds are listed as follows, (E)-1: (E)-1-(4-(phenyldiazenyl)phenyl)-1H-pyrrole-2,5-dione; (Z)-1: (Z)-1-(4-(phenyldiazenyl)phenyl)-1H-pyrrole-2,5dione; (E)-2: (E)-4-(2,5-dioxo-2H-pyrrol-1(5H)-yl)-N(4-(phenyldiazenyl)phenyl) benzamide; (Z)-2: (Z)-4-(2, 5-dioxo-2 $H$-pyrrol-1(5H)-yl)- $N$-(4-(phenyldiazenyl)phenyl) benzamide; (E)-3: (E)-1,1'-(4-(p-tolyldiazenyl)-1,3-phenylene)

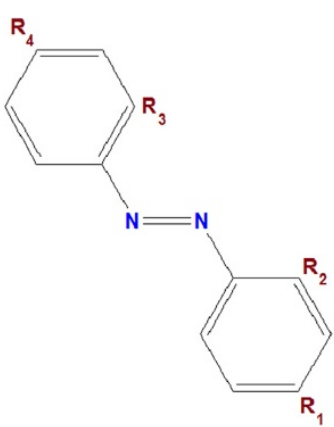

(E)

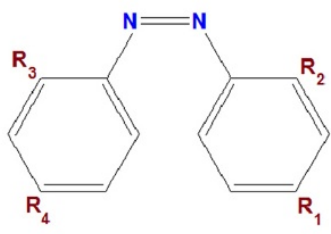

(Z)

\begin{tabular}{|c|c|c|c|c|}
\hline Compound & $\mathbf{R}_{1}$ & $\mathbf{R}_{2}$ & $\mathbf{R}_{3}$ & $\mathbf{R}_{4}$ \\
\hline 1 & & $-H$ & $-\mathrm{H}$ & $-\mathrm{H}$ \\
\hline 2 & $\mathrm{Ph}-\mathrm{C}$ & $-\mathrm{H}$ & $-\mathrm{H}$ & $-\mathrm{H}$ \\
\hline 3 & $-\mathrm{CH}$ & $-\mathrm{H}$ & & \\
\hline 4 & $-\mathrm{H}$ & $-\mathrm{CH}_{3}$ & & \\
\hline
\end{tabular}

Figure 1 Chemical structure of azobenzene derivatives considered for molecular modeling. 
bis(1H-pyrrole-2,5-dione); (Z)-3: (Z)-1,1'-(4-(p-tolyldiazenyl)-1,3-phenylene)bis(1H-pyrrole-2,5-dione); (E)-4: (E)-1,1'-(4-(o-tolyldiazenyl)-1,3-phenylene)bis(1H-pyrrole2,5-dione); (Z)-4: (Z)-1,1'-(4-(o-tolyldiazenyl)-1,3-phenylene)bis(1H-pyrrole-2,5-dione). The synthesis and characterization details (experimental part) of these azobenzene derivatives containing maleimide moieties have been reported previously (Airinei et al. 2010; Rusu et al. 2011; Hulubei \& Buiceac 2005; Airinei et al. 2011a, 2011b).

\section{Computational details}

All calculations based on semi-empirical molecular orbital theory have been carried out using HyperChem Release 8.0.6 molecular modeling software. The structures of the investigated azobenzene molecules in ground state were optimized using AM1 and PM3 semiempirical methods with restricted Hartree-Fock (RHF) basis. All calculations referred to isolated molecule (gas phase). In this respect, the conjugate gradients algorithm (Polak-Ribier) was employed for the geometry optimization using a convergence set to the value of 0.01 $\mathrm{kcal} /(\AA \mathrm{mol})$. The geometry optimization was done by minimization of the binding energy of the molecule. During energy minimization, it was searching for a molecular structure in which the energy did not change with infinitesimal changes in geometry and, respectively, the total root-mean-squared gradient (RMS-gradient) was close to zero. The optimal geometries of (E) and (Z) isomers were figured out starting from different initial conformers. The theoretical electronic absorption spectra of molecules were calculated on the optimized groundstate geometries using configuration-interaction (CI) method included in HyperChem.

In addition, Gaussian 03 program has been employed for more accurate calculation of the geometrical parameters of the molecules in ground state. To this end, the higher level quantum mechanics (QM) methods were employed, using the basis set $6-31+\mathrm{G}\left(\mathrm{d}, \mathrm{p}\right.$ ) (or $6-31+\mathrm{G}^{* *}$ ) with both polarization and diffuse functions, i.e. ab-initio $(\mathrm{RHF} / 6-31+\mathrm{G}(\mathrm{d}, \mathrm{p}))$ and density functional theory (B3LYP/ $6-31+G(d, p))$. Note that, polarization functions significantly improve the description of molecular geometries (bond lengths and angles) as well as molecular relative energies (Ramachandran et al. 2008). In fact, polarization functions add flexibility within basis set, effectively allowing molecular orbitals to be more asymmetric about the nucleus. The adding of diffuse function, represented by the "+" sign, is useful to take into account the effect of the electrons when they are far from the nucleus.

All programs have been running on Windows 7 operating system using a computer with the following characteristics: Intel Core i7, 2.4 GHz, 16GB RAM.

\section{Results and discussion}

\section{Optimized geometries and structural parameters}

Table 1 summarizes molecular information about the molecules subjected to modeling as well as some parameters computed by HyperChem. According to the results from Table 1, azobenzene derivatives containing maleimide groups are molecules with appreciable values of polarizabilities (30-43 $\AA^{3}$ ) and refractivities $\left(82-116 \AA^{3}\right.$ ) in their ground electronic state. The positive values of calculated partition coefficient $(\log P)$ suggest that azobenzene derivatives of concern are of hydrophobic nature.

Figure 2 shows 3D-optimized molecular structures of the azobenzene derivatives, $(\mathrm{E})$ and $(\mathrm{Z})$ isomers, in ground state computed with PM3 method. Likewise, the optimal geometries has been computed and by AM1 method. Table 2 compiles information on binding energies, gradients and heats of formation calculated by semi-empirical methods for each optimized conformer. The results of computation have revealed that $(\mathrm{E})-1$ is planar according to both AM1 and PM3, while (E)-2 is planar only according to AM1 model. These planar conformations correspond to $\mathrm{C}_{\mathrm{S}}$ molecular point group. All other investigated conformations are non-planar and correspond to $\mathrm{C}_{1}$ molecular point group.

Table 1 Some molecular information about modeled azo-derivatives

\begin{tabular}{|c|c|c|c|c|}
\hline Compound & 1 & 2 & 3 & 4 \\
\hline Empirical formula & $\mathrm{C}_{16} \mathrm{H}_{11} \mathrm{~N}_{3} \mathrm{O}_{2}$ & $\mathrm{C}_{23} \mathrm{H}_{16} \mathrm{~N}_{4} \mathrm{O}_{3}$ & $\mathrm{C}_{21} \mathrm{H}_{14} \mathrm{~N}_{4} \mathrm{O}_{4}$ & $\mathrm{C}_{21} \mathrm{H}_{14} \mathrm{~N}_{4} \mathrm{O}_{4}$ \\
\hline Molecular mass, (a.m.u.) & 277.28 & 396.40 & 386.37 & 386.37 \\
\hline Number of electrons (valence electrons + lone pairs) & 102 & 146 & 142 & 142 \\
\hline Number of double occupied molecular orbitals (OMO) & 51 & 73 & 71 & 71 \\
\hline Number of unoccupied (virtual) molecular orbitals (UMO) & 44 & 63 & 59 & 59 \\
\hline Number of total molecular orbitals $(\mathrm{OMO}+\mathrm{UMO})$ & 95 & 136 & 130 & 130 \\
\hline Polarizability, $\left(\AA^{3}\right)$ & 30.05 & 42.98 & 39.78 & 39.78 \\
\hline Refractivity, $\left(\AA^{3}\right)$ & 82.34 & 115.60 & 109.35 & 109.35 \\
\hline $\log P$ & 3.57 & 4.34 & 3.27 & 3.27 \\
\hline
\end{tabular}




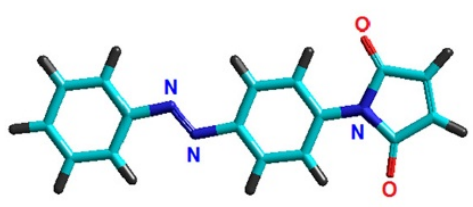

(E)-1

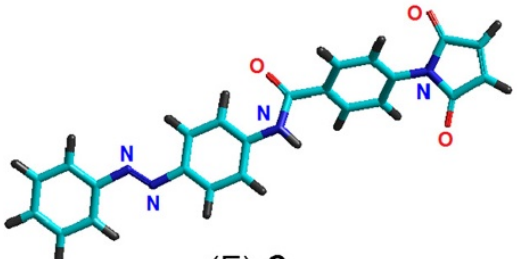

(E)-2

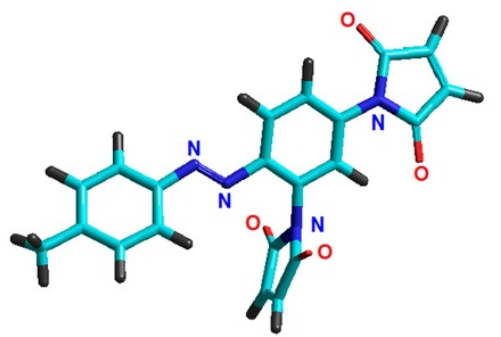

(E)-3

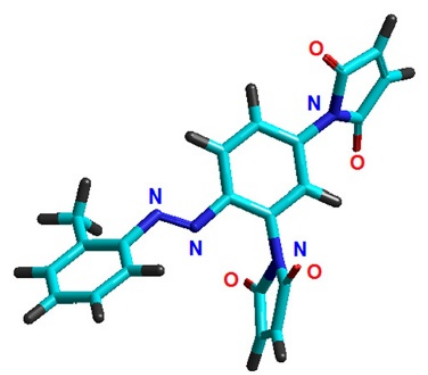

(E)-4

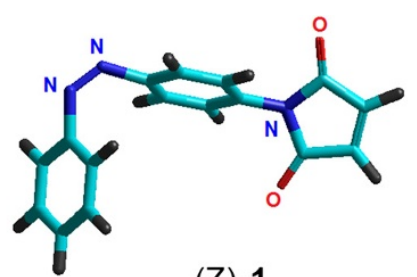

(Z)-1

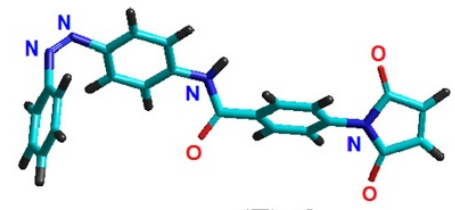

(Z) - 2

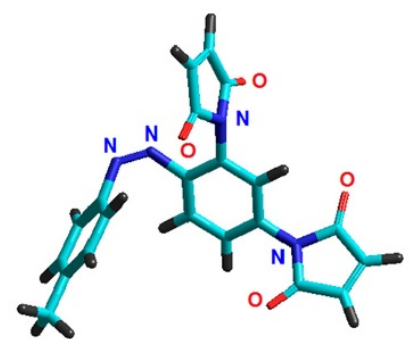

(Z)-3

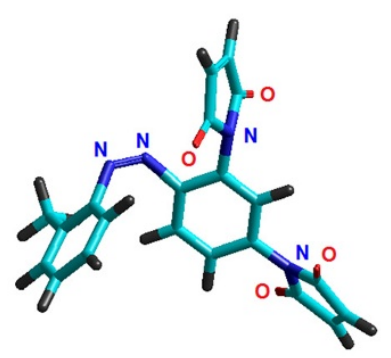

(Z)- 4

Figure 2 Optimized structures of azobenzene derivatives computed by PM3 method: tubes rendering model.

To determine which form is more stable $(\mathrm{E})$ or $(\mathrm{Z})$, the relative strain energy $\left(E_{r e l}\right)$ was calculated for each compound as the difference between binding energies of the isomers $(E)$ and $(Z)$. The relative strain energy $\left(E_{r e l}\right)$ may be also calculated and as the difference between heats of the formation of isomers (Shaabani \& Zahedi 2000). These computational results are focused in Table 3, pointing out that the energy is a function of molecular geometry. Thus, AM1 Hamiltonian shows that $(\mathrm{Z})$ isomers are more stable, while PM3 model suggests that $(E)$ isomers are the most stable. According to AM1 method, (Z) isomers are $4.97-6.80 \mathrm{kcal} / \mathrm{mol}$ more stable than (E) isomers. In contrast, PM3 model revealed that $(\mathrm{E})$ isomers are $0.25-1.73 \mathrm{kcal} / \mathrm{mol}$ more stable than $(Z)$ isomers. In order to disclose this inconsistency, we have done additional calculation of the relative strain energy $\left(E_{r e l}\right)$ by MNDO semi-empirical method as well as by ab-initio RHF/6-31+G(d,p) and $\mathrm{DFT} / \mathrm{B} 3 \mathrm{LYP} / 6-31+\mathrm{G}(\mathrm{d}, \mathrm{p})$. These results are also summarized in Table 3. Thus, the additional calculation using MNDO, ab-initio (RHF/6-31+G(d,p)) and DFT (B3LYP/ $6-31+G(d, p))$ methods are in agreement with PM3 model, revealing the stability of (E) isomers. Hence, PM3 method has proved better performance compared to AM1 method for molecular geometry optimization of azobenzene derivatives (1-4), due to its improved description of steric effects. This may be attributed to the fact that PM3 model was developed using a largely mathematical optimization procedures for parameterization of two electron repulsion integrals. Thus PM3 model, uses a Hamiltonian that is very similar to the AM1 Hamiltonian, but the parameterization strategy is 
Table 2 Calculated energy, gradient and heat of formation by semi-empirical methods for 1-4

\begin{tabular}{|c|c|c|c|c|}
\hline \multirow{2}{*}{ Compound } & \multicolumn{2}{|c|}{ (E) isomer } & \multicolumn{2}{|c|}{ (Z) isomer } \\
\hline & AM1 & PM3 & AM1 & PM3 \\
\hline \multicolumn{5}{|l|}{1} \\
\hline Binding Energy, (kcal/mol) & -3681.5595 & -3715.5188 & -3686.5290 & -3715.2679 \\
\hline RMS Gradient, (kcal/(Å mol)) & 0.0004869 & 0.0007137 & 0.005422 & 0.008860 \\
\hline Heat of formation (kcal/mol) & 83.9204 & 49.9612 & 78.9509 & 50.2120 \\
\hline Molecular point group & $C_{S}$ & $C_{S}$ & $\mathrm{C}_{1}$ & $C_{1}$ \\
\hline \multicolumn{5}{|l|}{2} \\
\hline Binding Energy, (kcal/mol) & -5313.0421 & -5355.8834 & -5319.0632 & -5354.1534 \\
\hline RMS Gradient, (kcal/(Å mol)) & 0.0001445 & 0.0010867 & 0.007611 & 0.009925 \\
\hline Heat of formation (kcal/mol) & 81.7368 & 38.8955 & 75.7157 & 40.6255 \\
\hline Molecular point group & $C_{S}$ & $C_{1}$ & $C_{1}$ & $C_{1}$ \\
\hline \multicolumn{5}{|l|}{3} \\
\hline Binding Energy, (kcal/mol) & -4945.5461 & -5009.5677 & -4951.5251 & -5009.1396 \\
\hline RMS Gradient, (kcal/(Å mol)) & 0.0007359 & 0.0013178 & 0.009186 & 0.009233 \\
\hline Heat of formation (kcal/mol) & 62.8079 & -1.2137 & 56.8288 & -0.7856 \\
\hline Molecular point group & $C_{1}$ & $C_{1}$ & $C_{1}$ & $C_{1}$ \\
\hline \multicolumn{5}{|l|}{4} \\
\hline Binding Energy, (kcal/mol) & -4944.8592 & -5009.6008 & -4951.6597 & -5008.1308 \\
\hline RMS Gradient, (kcal/(Å mol)) & 0.0004231 & 0.0007584 & 0.008362 & 0.009835 \\
\hline Heat of formation (kcal/mol) & 63.4948 & -1.2468 & 56.69429 & 0.223173 \\
\hline Molecular point group & $C_{1}$ & $C_{1}$ & $C_{1}$ & $C_{1}$ \\
\hline
\end{tabular}

different. Whereas AM1 model was parameterized largely based on a small number of atomic data, PM3 was parameterized to reproduce a large number of molecular properties (Ramachandran et al. 2008).

Table 4 summarizes the selected structural parameters calculated by semi-empirical methods for all molecules studied (1-4) in their isomeric forms (E) / (Z). The selected geometrical parameters reported in Table 4 involve bond lengths, valence angles and torsion angles related to azo group $(-\mathrm{N}=\mathrm{N}-)$ and adjacent carbon atoms $\left(\mathrm{Csp}^{2}\right)$. It can be observed from Table 4 that the calculated bond length of azo group $\mathrm{N}=\mathrm{N}$ is larger for (E) isomers than for $(\mathrm{Z})$ isomers. For instance, according to AM1 computations the bond length of $\mathrm{N}=\mathrm{N}$ is of $1.2313 \AA$ for (E)-1 isomer and of 1.2044 $\AA$ for (Z)-1 isomer. In contrast, the bond lengths $\mathrm{C}-\mathrm{N}$ and $\mathrm{N}-\mathrm{C}$ are larger for $(\mathrm{Z})$ isomers than for $(\mathrm{E})$ isomers. Likewise, the semi-empirical calculations revealed that the interatomic angles $\mathrm{C}-\mathrm{N}=\mathrm{N}$ and $\mathrm{N}=\mathrm{N}-\mathrm{C}$ are higher for $(\mathrm{Z})$ isomers comparing with $(\mathrm{E})$ isomers. For example, the valence angle $\mathrm{C}-\mathrm{N}=\mathrm{N}$ for $(\mathrm{Z})-1$ is of $129.46^{\circ}$ and $127.08^{\circ}$ according AM1 and PM3, respectively, while for (E)-1 isomer the same angle $\mathrm{C}-\mathrm{N}=\mathrm{N}$ is much smaller being of $119.73^{\circ}$ (AM1) and $119.88^{\circ}$ (PM3). The dihedral angle (torsion angle) $\mathrm{C}-\mathrm{N}=\mathrm{N}-\mathrm{C}$ is close to $180^{\circ}$ or $-180^{\circ}$ for all (E) isomers, while for $(\mathrm{Z})$ isomers this torsion angle is in the range of about $\pm 3^{\circ}$.

Compound (E)-1 was obtained experimentally in pure state as a light orange crystalline solid and its crystallographic data and experimental geometric parameters were reported (Rusu et al. 2011). It has been mentioned that the compound $1\left(\mathrm{C}_{16} \mathrm{H}_{11} \mathrm{~N}_{3} \mathrm{O}_{2}\right)$ displays a $(\mathrm{E})$ conformation

Table 3 Relative strain energy calculated for $(E)$ isomer to $(Z)$ isomer of azobenzene derivatives 1-4 by QM methods

\begin{tabular}{cccccc}
\hline \multirow{2}{*}{ Compound } & \multicolumn{4}{c}{$\mathbf{E}_{\text {rel }}(\mathbf{k c a l} / \mathbf{~ m o l})^{\mathbf{a})}$} \\
\cline { 2 - 6 } & AM1 & PM3 & MNDO & RHF / 6-31+G (d,p) & B3LYP / 6-31+G (d,p) \\
\hline 1 & 4.9695 & -0.2508 & -18.5492 & -14.6837 & -21.6789 \\
2 & 6.0211 & -1.7300 & -1.9715 & -16.8173 & -22.3017 \\
3 & 5.9791 & -0.4281 & -3.0078 & -12.4247 & -12.9393 \\
4 & 6.8006 & -1.4700 & -3.1976 & -14.3699 & -12.5628 \\
\hline
\end{tabular}

a) $E_{\text {rel }}=E_{E}-E_{Z}=H_{E}-H_{Z}$. 
Table 4 Summary of selected structural parameters related to azo-group atoms, for the compounds 1-4

\begin{tabular}{|c|c|c|c|c|c|c|c|c|c|}
\hline \multirow[t]{2}{*}{ Compound } & \multirow[t]{2}{*}{ Method } & \multicolumn{3}{|c|}{ Bond lengths } & \multicolumn{2}{|c|}{ Angles } & \multicolumn{3}{|c|}{ Torsions } \\
\hline & & C-N & $\mathrm{N}=\mathrm{N}$ & $\mathrm{N}-\mathrm{C}$ & $\mathrm{C}-\mathrm{N}=\mathrm{N}$ & $\mathrm{N}=\mathrm{N}-\mathrm{C}$ & $\mathrm{C}-\mathrm{C}-\mathrm{N}=\mathrm{N}$ & $\mathrm{C}-\mathrm{N}=\mathrm{N}-\mathrm{C}$ & $\mathrm{N}=\mathrm{N}-\mathrm{C}-\mathrm{C}$ \\
\hline \multirow{2}{*}{$(E)-1$} & AM1 & 1.4361 & 1.2313 & 1.4343 & 119.72 & 119.65 & 180 & 180 & 180 \\
\hline & PM3 & 1.4468 & 1.2319 & 1.4455 & 119.88 & 119.86 & 180 & 180 & 180 \\
\hline \multirow{2}{*}{ (Z)-1 } & AM1 & 1.4417 & 1.2044 & 1.4409 & 129.46 & 129.39 & -139.327 & 2.241 & 45.313 \\
\hline & PM3 & 1.4520 & 1.2160 & 1.4524 & 127.08 & 127.05 & -121.345 & 0.218 & 77.109 \\
\hline \multirow{2}{*}{ (E)-2 } & AM1 & 1.4363 & 1.2315 & 1.4332 & 119.68 & 119.73 & 180 & 180 & 180 \\
\hline & PM3 & 1.4471 & 1.2319 & 1.4452 & 119.78 & 119.90 & 169.061 & 179.896 & 174.997 \\
\hline \multirow{2}{*}{ (Z)-2 } & AM1 & 1.4434 & 1.2042 & 1.4386 & 129.37 & 129.58 & -117.574 & 1.683 & 31.229 \\
\hline & PM3 & 1.4527 & 1.2161 & 1.4517 & 127.06 & 127.19 & -95.658 & 0.187 & 61.950 \\
\hline \multirow{2}{*}{ (E)-3 } & AM1 & 1.4362 & 1.2302 & 1.4364 & 119.47 & 119.36 & 155.701 & 178.181 & -26.792 \\
\hline & PM3 & 1.4458 & 1.2313 & 1.4466 & 119.71 & 119.75 & -152.291 & -179.476 & 11.429 \\
\hline \multirow{2}{*}{ (Z)-3 } & AM1 & 1.4427 & 1.2038 & 1.4427 & 128.80 & 128.99 & 122.991 & -2.975 & -50.910 \\
\hline & PM3 & 1.4511 & 1.2168 & 1.4522 & 127.43 & 127.53 & -111.732 & 0.896 & 48.897 \\
\hline \multirow{2}{*}{ (E)-4 } & AM1 & 1.4390 & 1.2301 & 1.4344 & 118.50 & 120.22 & 41.406 & -177.189 & -1.464 \\
\hline & PM3 & 1.4476 & 1.2303 & 1.4482 & 119.48 & 119.75 & 45.337 & -179.005 & 15.011 \\
\hline \multirow{2}{*}{ (Z)-4 } & AM1 & 1.4442 & 1.2037 & 1.4429 & 128.73 & 128.83 & 71.141 & 3.149 & 50.208 \\
\hline & PM3 & 1.4517 & 1.2168 & 1.4523 & 127.60 & 127.57 & 75.351 & 1.815 & 49.968 \\
\hline
\end{tabular}

with respect to azo group and the molecule is non-planar. Thus, one of the goals of this work was to calculate geometrical parameters for (E)-1 and to compare with available experimental data. In this respect, in addition to HyperChem semi-empirical calculations (AM1 and PM3), the Gaussian program has been employed for more accurate computations of the geometrical parameters in ground state using higher level QM methods, such as ab-initio (RHF/6-31+G(d,p)) and density functional calculations (DFT/B3LYP/6-31+G(d,p)). Figure 3 shows the optimized molecular structure of (E)-1 azobenzene derivative $\left(\mathrm{C}_{16} \mathrm{H}_{11} \mathrm{~N}_{3} \mathrm{O}_{2}\right)$ computed by $\mathrm{AM} 1$ model. In this figure, the ball and stick rendering model with full atomic numbering has been used for spatial representation.
Table 5 summarizes the selected bond lengths and interatomic angles for (E)-1 $\left(\mathrm{C}_{16} \mathrm{H}_{11} \mathrm{~N}_{3} \mathrm{O}_{2}\right)$ computed by quantum-mechanics methods (QM) and compared with experimental values. Note that in Table 5 only a part of geometrical parameters are reported. In fact, a total number of 33 bond lengths and 53 interatomic angles have been determined by X-ray structure analysis (Rusu et al. 2011), and the corresponding counterparts of these geometrical parameters have been calculated in this work by QM methods. For a more compact representation, all these results (experimental and calculated) are shown as histograms in Figures 4 and 5. These histograms illustrate the distributions of bond lengths and valence angles for (E)-1 molecule in accordance with the

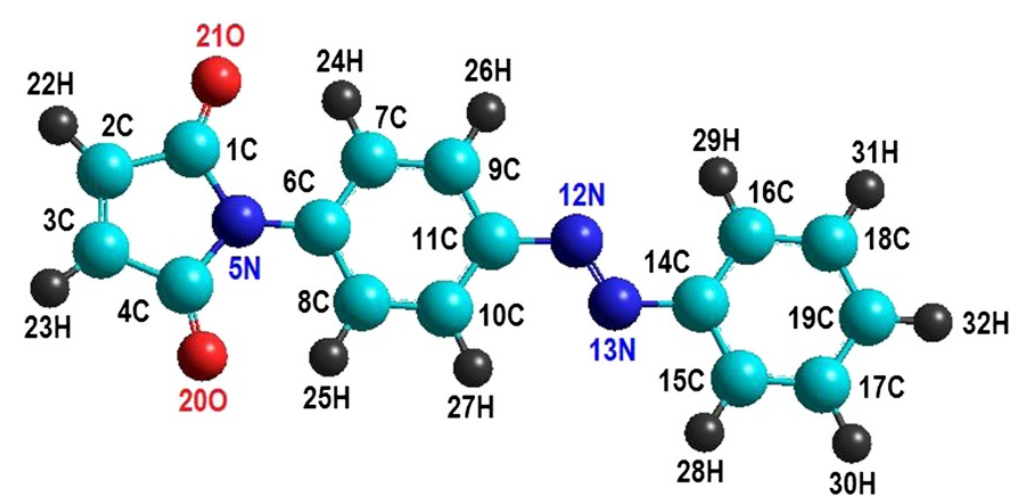

Figure 3 Optimized molecular structures of $(\mathrm{E})-1$ azobenzene derivative, in ground state $\left(\mathrm{S}_{0}\right)$, computed by $\mathrm{AM} 1$ method: - balls and sticks rendering model with full atomic numbering. 
Table 5 Selected bond lengths (in $\AA$ ) and interatomic angles (in deg ${ }^{\circ}$ ) computed for $(E)-1\left(\mathrm{C}_{16} \mathrm{H}_{11} \mathrm{~N}_{3} \mathrm{O}_{2}\right)$ by QM methods and comparison with experimental values

\begin{tabular}{|c|c|c|c|c|c|}
\hline Geometry & Experim $^{\text {a) }}$ & AM1 & PM3 & $\begin{array}{c}\text { RHF } \\
6-31+G(d, p)\end{array}$ & $\begin{array}{c}\text { B3LYP } \\
6-31+G(d, p)\end{array}$ \\
\hline \multicolumn{6}{|c|}{ Bond } \\
\hline $12 \mathrm{~N}-13 \mathrm{~N}$ & 1.2539 & 1.2313 & 1.2319 & 1.2183 & 1.2589 \\
\hline $12 \mathrm{~N}-11 \mathrm{C}$ & 1.4320 & 1.4343 & 1.4455 & 1.4192 & 1.4161 \\
\hline $5 \mathrm{~N}-1 \mathrm{C}$ & 1.4046 & 1.4329 & 1.4581 & 1.4021 & 1.4219 \\
\hline $5 N-4 C$ & 1.4049 & 1.4330 & 1.4583 & 1.4023 & 1.4223 \\
\hline $5 \mathrm{~N}-6 \mathrm{C}$ & 1.4346 & 1.4108 & 1.4420 & 1.4356 & 1.4351 \\
\hline $200-4 C$ & 1.2062 & 1.2302 & 1.2127 & 1.1864 & 1.2137 \\
\hline $7 C-9 C$ & 1.3845 & 1.3876 & 1.3889 & 1.3864 & 1.3926 \\
\hline $7 C-6 C$ & 1.3918 & 1.4143 & 1.4003 & 1.3916 & 1.4062 \\
\hline $7 \mathrm{C}-24 \mathrm{H}$ & 0.9300 & 1.1024 & 1.0972 & 1.0666 & 1.0787 \\
\hline $13 N-14 C$ & 1.4252 & 1.4360 & 1.4468 & 1.4216 & 1.4189 \\
\hline $10 C-8 C$ & 1.3781 & 1.3889 & 1.3862 & 1.3805 & 1.3885 \\
\hline $10 C-11 C$ & 1.396 & 1.4070 & 1.3994 & 1.3897 & 1.4042 \\
\hline $10 \mathrm{C}-27 \mathrm{H}$ & 0.9300 & 1.1028 & 1.0972 & 1.0725 & 1.0837 \\
\hline $8 C-6 C$ & 1.3893 & 1.4134 & 1.4033 & 1.3993 & 1.4117 \\
\hline $9 C-11 C$ & 1.3874 & 1.4104 & 1.3997 & 1.3821 & 1.3992 \\
\hline $9 \mathrm{C}-26 \mathrm{H}$ & 0.9300 & 1.1028 & 1.0973 & 1.0747 & 1.0855 \\
\hline $14 C-15 C$ & 1.3879 & 1.4129 & 1.4012 & 1.3863 & 1.4025 \\
\hline $14 C-16 C$ & 1.3952 & 1.4093 & 1.3992 & 1.3937 & 1.4072 \\
\hline $210-1 C$ & 1.2044 & 1.2302 & 1.2099 & 1.1865 & 1.2138 \\
\hline \multicolumn{6}{|c|}{ Angle } \\
\hline $13 \mathrm{~N}-12 \mathrm{~N}-11 \mathrm{C}$ & 112.96 & 119.65 & 119.86 & 115.83 & 115.13 \\
\hline $1 C-5 N-4 C$ & 109.32 & 108.15 & 107.37 & 108.25 & 107.86 \\
\hline $1 C-5 N-6 C$ & 125.35 & 125.93 & 128.18 & 125.78 & 125.99 \\
\hline $4 C-5 N-6 C$ & 125.18 & 125.91 & 124.44 & 125.96 & 126.14 \\
\hline $9 C-7 C-6 C$ & 119.44 & 121.03 & 119.88 & 119.90 & 119.82 \\
\hline $9 \mathrm{C}-7 \mathrm{C}-24 \mathrm{H}$ & 120.30 & 117.68 & 118.25 & 119.06 & 119.65 \\
\hline $6 \mathrm{C}-7 \mathrm{C}-24 \mathrm{H}$ & 120.30 & 121.28 & 121.87 & 121.03 & 120.53 \\
\hline $12 \mathrm{~N}-13 \mathrm{~N}-14 \mathrm{C}$ & 113.94 & 119.72 & 119.88 & 115.95 & 115.27 \\
\hline $8 C-10 C-11 C$ & 120.04 & 121.19 & 119.81 & 120.56 & 120.64 \\
\hline $8 \mathrm{C}-10 \mathrm{C}-27 \mathrm{H}$ & 120.00 & 118.26 & 119.01 & 119.46 & 119.99 \\
\hline $11 \mathrm{C}-10 \mathrm{C}-27 \mathrm{H}$ & 120.00 & 120.54 & 121.18 & 119.98 & 119.36 \\
\hline $10 C-8 C-6 C$ & 119.80 & 120.92 & 120.44 & 120.52 & 120.41 \\
\hline $10 \mathrm{C}-8 \mathrm{C}-25 \mathrm{H}$ & 120.10 & 117.76 & 120.43 & 118.82 & 119.43 \\
\hline
\end{tabular}

a) Experimental X-ray crystal data from (Rusu et al. 2011).

experimental observations and theoretical models. Both experimental evidences and theoretical computations revealed that the shortest bond lengths were attributed to the bonds $\mathrm{C}-\mathrm{H}$. According to X-ray structure analysis $\mathrm{C}-\mathrm{H}$ bond is of length of $0.93 \AA$ whereas the theoretical models predict a larger bond length for $\mathrm{C}-\mathrm{H}$ of about $1.07-1.09 \AA$. The largest bond length in the molecule
(E)-1 is attributed to $\mathrm{C}-\mathrm{C}$ bond from maleimide group. Thus, according to experimental evidence the largest bond length is of $1.4893 \AA$ being ascribed to $4 \mathrm{C}-3 \mathrm{C}$ bond. The theoretical models also predict that $4 \mathrm{C}-3 \mathrm{C}$ bond has the largest length being of $1.5138 \AA$, $1.4937 \AA$ and $1.4952 \AA$ according to AM1, RHF/6-31+G(d,p) and $\mathrm{B} 3 \mathrm{LYP} / 6-31+\mathrm{G}(\mathrm{d}, \mathrm{p})$ methods, respectively. In accordance with semi-empirical method PM3, the largest bond length is $1 C-2 C$ with the value of $1.5039 \AA$. The histogram from Figure 4 shows that the highest frequency corresponds to the bin interval of 1.319-1.417 $\AA$, being attributed to $\mathrm{C}-\mathrm{C}$ and $\mathrm{C}-\mathrm{N}$ bond types. Regarding interatomic angles, the smallest valence angle given by X-ray structure analysis is of $106.12^{\circ}$ and corresponds to $5 \mathrm{~N}$ $4 \mathrm{C}-3 \mathrm{C}$ from maleimide group. According to theoretical geometry optimization calculations using AM1, RHF/6$31+\mathrm{G}(\mathrm{d}, \mathrm{p})$ and $\mathrm{B} 3 \mathrm{LYP} / 6-31+\mathrm{G}(\mathrm{d}, \mathrm{p})$ methods, the valence angle $5 \mathrm{~N}-4 \mathrm{C}-3 \mathrm{C}$ is also the smallest one and has the following values of $107.12^{\circ}, 107.17^{\circ}$ and $107.21^{\circ}$, respectively. The PM3 computations suggest that the smallest valence angle in molecule (E)-1 is $5 \mathrm{~N}-1 \mathrm{C}-2 \mathrm{C}$ from maleimide group, being of $106.51^{\circ}$. In accordance with $\mathrm{X}$-ray-structure analysis of (E)-1, the largest interatomic angle is $21 \mathrm{O}-1 \mathrm{C}-2 \mathrm{C}$, which has the value of $128.17^{\circ}$. The theoretical models predict for this angle $21 \mathrm{O}-1 \mathrm{C}-2 \mathrm{C}$ the values ranging from $125.04^{\circ}$ to $127.51^{\circ}$. According to optimized geometries computed by QM methods the largest valence angle is $2 \mathrm{C}-3 \mathrm{C}-23 \mathrm{H}$ which is equal to theoretical values of $130.85^{\circ}$ (AM1), $128.37^{\circ}$ (PM3), $130.20^{\circ}(\mathrm{RHF} / 6-31+\mathrm{G}(\mathrm{d}, \mathrm{p}))$ and $130.15^{\circ}$ (B3LYP/6-31+G $(\mathrm{d}, \mathrm{p}))$. The histogram shown in Figure 5 indicates that the highest frequency (count) corresponds to the bin interval of $116.72^{\circ}-120.25^{\circ}$, which is mainly attributed to the interatomic angles of type $\mathrm{C}-\mathrm{C}-\mathrm{H}$ and $\mathrm{C}-\mathrm{C}-\mathrm{C}$.

In order to estimate the goodness-of-fit between experimental and theoretical parameters (i.e. bond lengths, valence angles) corresponding to (E)-1 molecule, the residual error functions (deviation errors) have been computed in terms of root-mean-square deviation (RMSD) and average relative error $(A R E)$ as follows:

$$
\begin{aligned}
& R M S D=\sqrt{\frac{1}{(N-1)} \sum_{i-1}^{N}\left(X_{i}^{\text {calc }}-X_{i}^{\exp }\right)^{2}} \\
& A R E=\frac{100}{N} \sum_{i=1}^{N}\left(\frac{\left|X_{i}^{\exp }-X_{i}^{\text {calc }}\right|}{X_{i}^{\exp }}\right)
\end{aligned}
$$

where $N$ is the number of data, $X^{\exp }$ denotes the experimental parameter (i.e. bond length, valence angle, etc.) and $X^{\text {calc }}$ is the theoretical parameter calculated by QM method. Table 6 summarizes the values of RMSD and $A R E$ to compare the abilities of QM methods for prediction and fitting experimental data related to bond lengths 


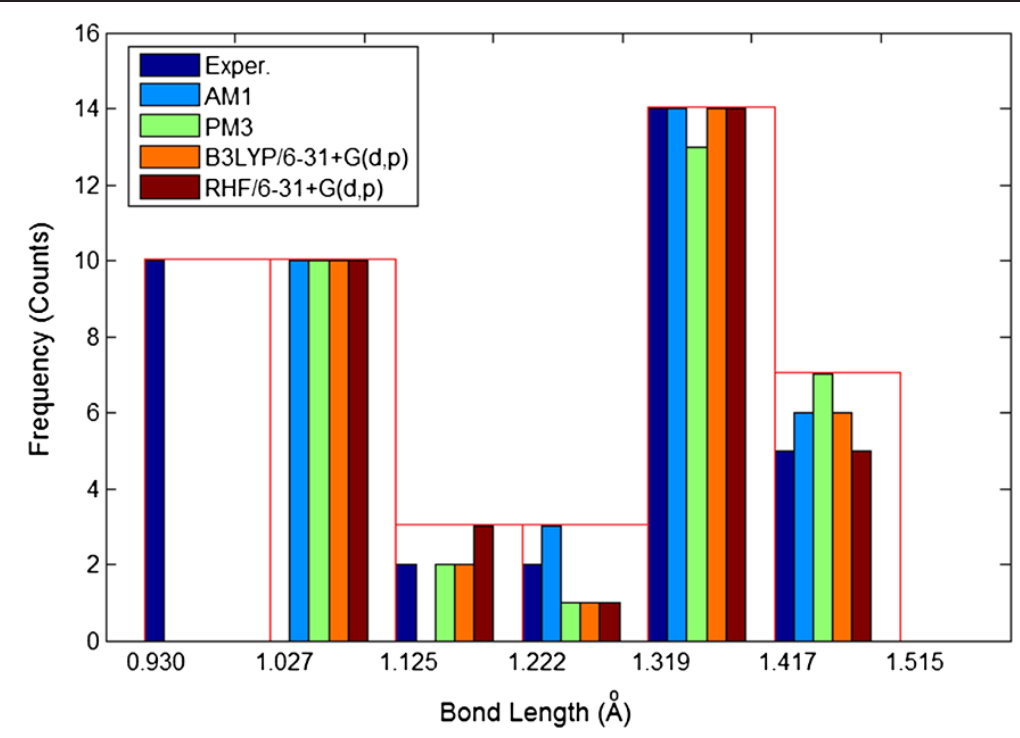

Figure 4 Histogram of bonds length distribution determined for (E)-1 azobenzene derivative: crystallographic data (experimental) versus $\mathrm{QM}$-calculations.

and angles of (E)-1 azobenzene derivative. According to the results reported in Table 6, the best methods for predicting the structural parameters of (E)-1 are ab-initio at the level RHF/6-31+G(d,p) and DFT/B3LYP/6-31+G(d,p) followed by semi-empirical methods PM3 and AM1. Thus, ab initio calculations atRHF/6-31+G(d,p) level bestowed more accurate results on (E)-1 structure giving a deviation error from crystallographic data of about 5.00\% for bond lengths and $0.97 \%$ for interatomic angles.
The density functional computations at the level B3LYP/ $6-31+G(d, p)$ have predicted the geometry of (E)-1 in gas phase with the deviation errors from crystallographic data of about $5.60 \%$ for bond lengths and $0.95 \%$ for valence angles. In case of semi-empirical calculations of structural parameters by AM1 and PM3 methods, the residual errors are of $6.44 \%, 6.11 \%$ for bond lengths and $1.33 \%, 0.94 \%$ for interatomic angles, respectively (Table 6). Thus, PM3 method predicts better the structural parameters of (E)-1

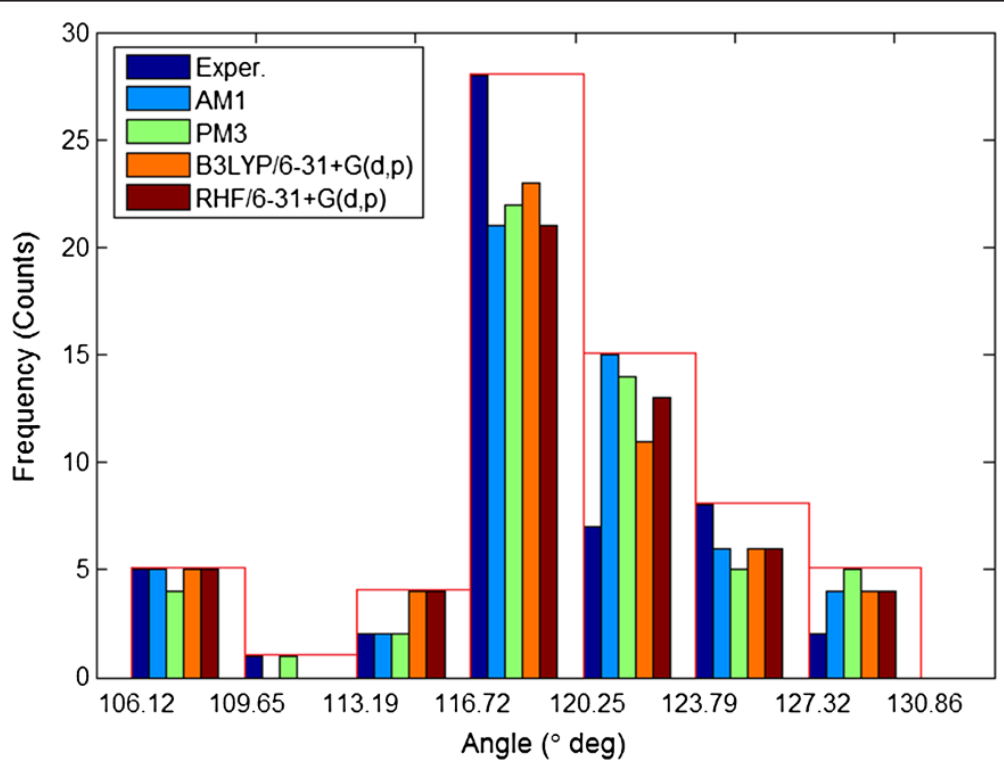

Figure 5 Histogram of interatomic angles distribution determined for (E)-1 azobenzene derivative: crystallographic data (experimental) versus QM-calculations. 
Table 6 Root mean square deviation (RMSD) and average relative error (ARE) used for ascertaining the goodness-of-fit between observed and predicted bond lengths and angles for the molecule $(E)-1\left(\mathrm{C}_{16} \mathrm{H}_{11} \mathrm{~N}_{3} \mathrm{O}_{2}\right)$

\begin{tabular}{ccccc}
\hline & AM1 & PM3 & B3LYP / 6-31+G(d,p) & RHF / 6-31+G(d,p) \\
\hline & & Bond lengths & \\
RMSD, $(\AA)$ & 0.3567 & 0.3428 & 0.3111 & 0.2401 \\
ARE, (\%) & 6.4427 & 6.1093 & 5.5991 & 5.0003 \\
& & Interatomic angles & \\
RMSD, (deg $\left.{ }^{\circ}\right)$ & 1.7406 & 1.7903 & 0.4967 & 0.6867 \\
ARE, $(\%)$ & 1.3338 & 0.9386 & 0.9478 & 0.9692 \\
\hline
\end{tabular}

comparing with AM1. All calculations (AM1, PM3, RHF/ $6-31+G(d, p)$ and B3LYP/6-31+G(d,p)) performed in this work have revealed that the molecule (E)-1 is planar from theoretical standpoint. In contrast, the X-ray data offered a non-planar geometry for the same molecule (Rusu et al. 2011). For instance, the torsion angle $1 \mathrm{C}-5 \mathrm{~N}-6 \mathrm{C}-8 \mathrm{C}$ is of $180^{\circ}$ according to the theoretical predictions, but the same dihedral angle is of $140.32^{\circ}$ according to crystallographic data. Also, it has been reported by X-ray structure analysis a torsion angle of $21.5^{\circ}$ for $13 \mathrm{~N}-12 \mathrm{~N}-11 \mathrm{C}-10 \mathrm{C}$ (Rusu et al. 2011), whereas our theoretical computations have indicated for the same dihedral angle a value of $0^{\circ}$. All four planar geometries of (E)-1 computed by QM methods have converged to the same values of torsion angles. The discrepancy between theory and experiment on the planar geometry of (E)-1 may be attributed to the fact that all theoretical computations have been performed for an isolated molecule in vacuum. By contrast, according to experimental observations (i.e. crystallographic data) the molecules of (E)-1 in the crystal are stacked along the [100] direction with a mean interplanar distance of 3.857 (1) $\AA$ and, additionally, C-H...O interactions link them into double layers parallel to the ac-plane (Rusu et al. 2011). Such interactions existing into the crystal may affect the planarity of (E)-1, turning the geometry of this molecule into the non-planar one.

\section{Charge distribution, electrostatic potential and QSAR properties}

The population analysis in computational chemistry stands for estimating by calculation of the partial atomic charges of the studied molecule (Ramachandran et al. 2008). The Mulliken population analysis is the most common type of such computation and HyperChem makes use of it. The atomic charge distribution in the molecule is of great importance and has a significant impact on electrostatic potential, dipole moment and theoretical absorption spectra. Figure 6 shows the atomic charges distribution in molecule (E)-1 computed by semi-empirical methods AM1 (Figure 6a) and PM3 (Figure 6b). As one can see from Figure 6, the highest positive net charges are attributed to $1 \mathrm{C}$ and $4 \mathrm{C}$ atoms. All hydrogen atoms have positive charges. The oxygen heteroatoms 200 and 210 are assigned with strong negative charges. Also, nitrogen heteroatoms $5 \mathrm{~N}, 12 \mathrm{~N}$ and $13 \mathrm{~N}$ have the negative charges that are stronger according to AM1 computations comparing with PM3. Note that, the atomic charges distributions have been calculated for all azobenzene derivatives (1-4). In this respect, Table 7 gives the net charges for selected central atoms $\mathrm{C}-\mathrm{N}=\mathrm{N}-\mathrm{C}$ related to azo group and the adjacent carbons of $\mathrm{sp}^{2}$ hybridization $\left(\mathrm{Csp}^{2}\right)$. According to both semi-empirical methods (AM1 and PM3), the calculated atomic charges for azo nitrogen atoms $(\mathrm{N}=\mathrm{N})$ are smaller in case of all (E) isomers as compared to (Z) isomers. The switching to $(Z)$ isomers will increase the net charges of nitrogen atoms from azo group $(\mathrm{N}=\mathrm{N})$. For example, according to AM1 calculations for (E)-1 molecule, the net charges of nitrogen atoms $(\mathrm{N}=\mathrm{N})$ are equal to -0.0662 and -0.0723 . The switching to $(Z)-1$ isomer will increase the atomic charges of nitrogen atoms to the values +0.0061 and +0.0031 , respectively. The carbon atoms $\mathrm{C}$ - $\mathrm{sp}^{2}$ linked to azo group are more negatively charged for $(Z)$ isomers comparing with (E) isomers (Table 7).

Based on atomic charge distributions, the electrostatic potential surface (ESP) surrounding the molecule has been computed by HyperChem using a grid-points technique. Electrostatic potential is useful for finding sites of reaction in a molecule: positively charged species (e.g. $\left.\mathrm{H}^{+}\right)$ tend to attack the sites where the electrostatic potential is strongly negative (electrophilic attack). Figure 7 illustrates a three-dimensional (3D) mapped isosurface of the electrostatic potential surrounding (E)-1 molecule that has been computed at the level of AM1 method. The red colors indicate negative ESP regions followed by green colors which denote slightly positive ESP regions and blue colors indicating strong positive ESP regions. As one can see from Figure 7, oxygen heteroatoms 200 and 210 have the highest negative ESP regions, being the sites for electrophilic attack. Also, the isosurface plot shows that nitrogen heteroatoms $12 \mathrm{~N}$ and $13 \mathrm{~N}$ of azo bridge have 


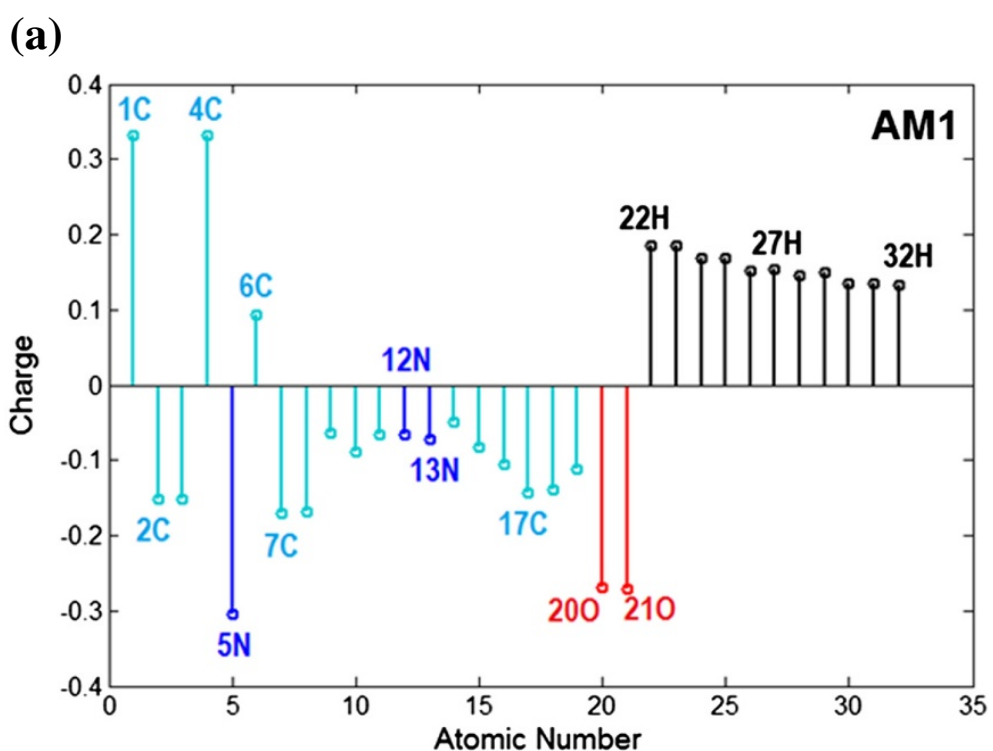

(b)

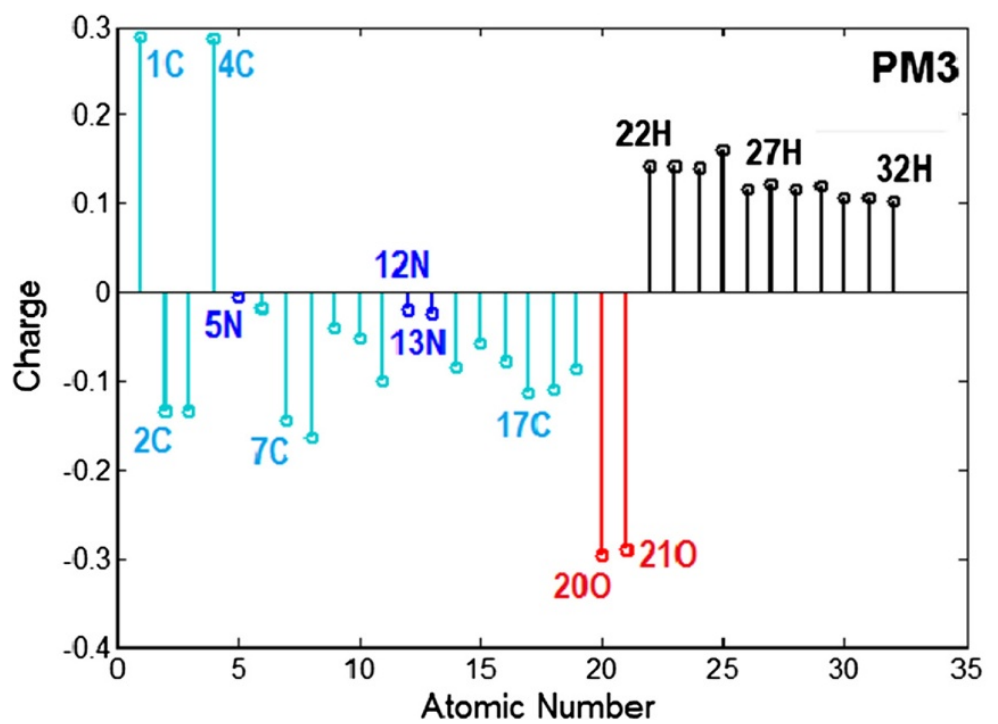

Figure 6 Atomic charges distribution in molecule (E)-1 computed by semi-empirical methods: (a) AM1 and (b) PM3.

more negative ESP regions than nitrogen heteroatom $5 \mathrm{~N}$ from maleimide group. Whenever lone pair $(n)$-containing heteroatoms are part of a double-bonded system, they may undergo protonation under acidic conditions. Thus, the computed ESP predicts that in the acidic medium, the protonation reaction will occur preferable on nitrogen atoms from azo group and not on nitrogen atom from maleimide moiety. The electrostatic potential levels (i.e. minimum and maximum values) for all azobenzene derivatives (1-4) are reported in Table 8 . In addition, Table 8 lists the dipole moment values as well as some quantitative structure-activity relationship (QSAR) properties computed at the level of semi-empirical Hamiltonians
(AM1 and PM3). The results presented in Table 8 reveal that, dipole moments values $(D M)$ are higher for $(\mathrm{Z})$ isomers than for (E) isomers. For instance, in case of (E)-1 isomer the dipole moment is of $2.052 \mathrm{D}$ according to AM1 method, whereas for ( $\mathrm{Z})-1$ isomer $D M$ value is higher being equal to 4.755 D (AM1). The surface areas and volumes of molecules (1-4) have been calculated by numerical integration grid techniques included in HyperChem. The computational results from Table 8 indicate that surface areas and volumes are higher for (E) isomers than for corresponding (Z) isomers. According to X-ray-structure analysis reported in Ref. (Rusu et al. 2011) the molecular volume for the isomer $(\mathrm{E})-1$ is about $650.18\left(\AA^{3}\right)$, which is smaller about $24 \%$ 
Table 7 Net charges of atoms related to azo group and adjacent carbons ( $\mathrm{C}-\mathrm{N}=\mathrm{N}-\mathrm{C}$ ) computed by semi-empirical methods for 1-4

\begin{tabular}{lccccc}
\hline \multicolumn{2}{c}{ Compound } & $\mathbf{C}\left(\mathbf{s p}^{\mathbf{2}}\right)$ & $\mathbf{N}$ & $\mathbf{N}$ & $\mathbf{C}\left(\mathbf{s p}^{\mathbf{2}}\right)$ \\
\hline \multirow{2}{*}{ (E)-1 } & AM1 & -0.0653 & -0.0662 & -0.0723 & -0.0482 \\
& PM3 & -0.1006 & -0.0192 & -0.0249 & -0.0834 \\
(Z)-1 & AM1 & -0.1206 & 0.0061 & 0.0031 & -0.1091 \\
& PM3 & -0.1063 & 0.0334 & 0.0386 & -0.1177 \\
(E)-2 & AM1 & -0.0806 & -0.0654 & -0.0757 & -0.0458 \\
& PM3 & -0.1082 & -0.0180 & -0.0263 & -0.0810 \\
(Z)-2 & AM1 & -0.1441 & 0.0102 & -0.0040 & -0.0996 \\
& PM3 & -0.1274 & 0.0347 & 0.0350 & -0.1090 \\
(E)-3 & AM1 & -0.0523 & -0.0675 & -0.0524 & -0.0519 \\
& PM3 & -0.0859 & -0.0351 & -0.0008 & -0.0905 \\
& AM1 & -0.1122 & 0.0006 & 0.0187 & -0.1148 \\
(Z)-3 & PM3 & -0.1062 & 0.0077 & 0.0542 & -0.1297 \\
& AM1 & -0.0609 & -0.0635 & -0.0583 & -0.0465 \\
(E)-4 & PM3 & -0.0745 & -0.0347 & 0.0083 & -0.0812 \\
& AM1 & -0.1120 & 0.0035 & 0.0197 & -0.1090 \\
(Z)-4 & PM3 & -0.1059 & 0.0074 & 0.0574 & -0.1224 \\
& & & & &
\end{tabular}

than the predicted volumes calculated at the level of semiempirical Hamiltonians. The hydration energy $\left(E_{H}\right)$ calculated for azobenzene derivatives (1-4) ranged from -13.06 $\mathrm{kcal} / \mathrm{mol}$ to $-5.91 \mathrm{kcal} / \mathrm{mol}$ (Table 8).

\section{Electronic properties}

The information regarding number of electrons, number of double occupied molecular orbitals and virtual molecular orbitals are summarized in Table 1 for each studied azobenzene derivative (1-4). The energy spectra of molecular orbitals (MOs) in ground state have been computed for all molecules (1-4) by means of semiempirical methods (AM1 and PM3). Figure 8 shows as an example the energy spectrum of MOs calculated for (E)-1 in its ground state $\left(\mathrm{S}_{0}\right)$ at the level of AM1 model. As can be observed, for each molecular orbital the corresponding energy value ( $\varepsilon_{j}$-eigenvalue) and orbital index $\left(\Psi_{\mathrm{j}}\right)$ are associated. The green lines indicate the eigenvalues of occupied molecular orbitals (OMO), while the pink lines denote the energy levels of unoccupied (virtual) orbitals (UMO). Such spectra give useful information about the energy values of frontier molecular orbitals and the corresponding energy gap $\Delta E$.

The eigenvalues of highest occupied molecular orbital (HOMO) and lowest unoccupied molecular orbital (LUMO) give information about the chemical activity and stability of the molecule, and are important parameters from quantum chemistry standpoint. The frontier orbital HOMO as an electron donor reflects the ability of the molecule to donate an electron, whereas LUMO as an electron acceptor represents the ability to receive an electron (Jesintha John et al. 2012; Mahadevan et al. 2012).

Based on theoretical MOs energy spectra the following molecular descriptors have been computed, namely, ionization potential $(I P)$, electron affinity $(E A)$, electronegativity $(X)$, chemical hardness $(\eta)$ and electrophilicity index $(\omega)$. Following the standard procedure based on Koopmans' theorem, the ionization potential and electron affinity have been calculated from the energy values of the highest occupied and the lowest unoccupied molecular orbitals, respectively, i.e. $I P \approx-\varepsilon_{\mathrm{HOMO}}$ and $E A \approx-\varepsilon_{\text {LUMO }}$ (Fayet et al. 2010; Ramachandran et al. 2008; Hurjui et al. 2013). The molecular descriptor related to electronegativity $(\chi)$ characterizes the electron donor/acceptor behavior of the molecule being calculated as (Fayet et al. 2010; Hurjui et al. 2013):

$$
\chi=\frac{I P+E A}{2}
$$

Note that electronegativity is equal, but opposite in sign, to the chemical potential $(\mu)$, i.e. $\mu=-\chi$. The chemical hardness $(\eta)$ and electrophilicity index $(\omega)$ have been computed using the following formulas (Fayet et al. 2010; Hurjui et al. 2013):

$$
\eta=\frac{I P-E A}{2}
$$

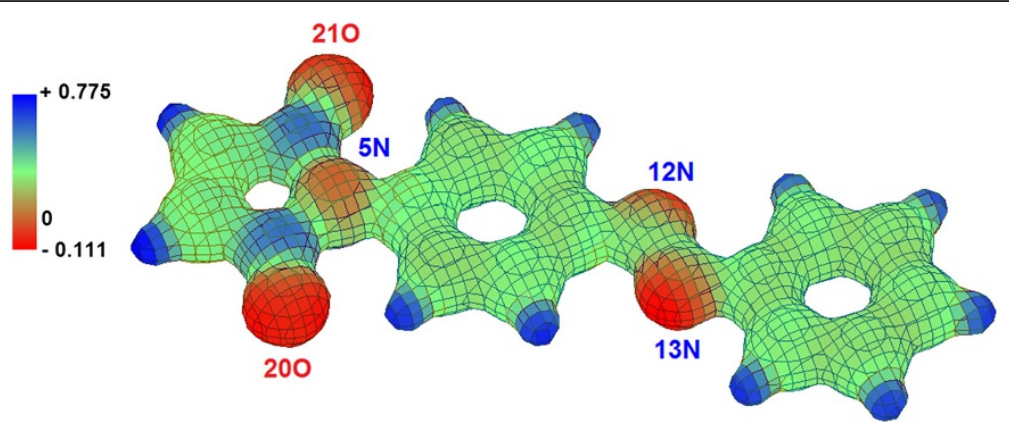

Figure 7 Isosurface plot of the electrostatic potential (ESP) in the spatial vecinity of (E)-1 azobenzene derivative: AM1 computation results. 
Table 8 Dipole moments, electrostatic potential levels and some QSAR properties of 1-4, computed at the level of semi-empirical methods

\begin{tabular}{|c|c|c|c|c|c|c|c|c|}
\hline \multicolumn{2}{|c|}{ Compound } & \multirow{2}{*}{$\begin{array}{c}\text { DM (Debye) } \\
2.052\end{array}$} & \multirow{2}{*}{$\begin{array}{c}\text { ESP-min } \\
-0.111\end{array}$} & \multirow{2}{*}{$\frac{\text { ESP-max }}{0.775}$} & \multirow{2}{*}{$\begin{array}{c}\text { a)Size, }(\AA ̊) \\
14.977\end{array}$} & \multirow{2}{*}{$\begin{array}{c}\text { Surf. area, }\left(\AA^{2}\right) \\
498.66\end{array}$} & \multirow{2}{*}{$\frac{\text { Volume, }\left(\AA^{3}\right)}{810.26}$} & \multirow{2}{*}{$\frac{\mathrm{E}_{\mathrm{H}},(\mathrm{kcal} / \mathrm{mol})}{-8.78}$} \\
\hline & $\mathrm{AM} 1$ & & & & & & & \\
\hline$(\text { (L) })^{-1}$ & PM3 & 1.983 & -0.115 & 0.491 & 15.023 & 498.21 & 808.06 & -8.59 \\
\hline \multirow{2}{*}{$(\mathrm{Z})-1$} & $\mathrm{AM} 1$ & 4.755 & -0.104 & 0.075 & 12.379 & 486.23 & 792.71 & -9.61 \\
\hline & PM3 & 4.252 & -0.094 & 0.069 & 12.012 & 498.21 & 807.64 & -9.49 \\
\hline \multirow{2}{*}{ (E)-2 } & $\mathrm{AM} 1$ & 5.652 & -0.120 & 0.122 & 21.538 & 666.20 & 1113.99 & -12.24 \\
\hline & PM3 & 4.729 & -0.140 & 0.521 & 21.415 & 675.13 & 1126.70 & -12.10 \\
\hline \multirow{2}{*}{ (Z)-2 } & $\mathrm{AM} 1$ & 7.173 & -0.124 & 0.318 & 17.963 & 658.69 & 1105.88 & -13.06 \\
\hline & PM3 & 5.517 & -0.130 & 0.498 & 16.894 & 674.06 & 1120.41 & -12.99 \\
\hline \multirow{2}{*}{$(E)-3$} & $\mathrm{AM} 1$ & 1.091 & -0.127 & 0.350 & 15.888 & 624.97 & 1056.08 & -6.22 \\
\hline & PM3 & 0.723 & -0.130 & 0.485 & 15.821 & 628.07 & 1054.64 & -6.09 \\
\hline \multirow{2}{*}{$(\mathrm{Z})-3$} & $\mathrm{AM} 1$ & 3.598 & -0.116 & 0.370 & 13.044 & 605.12 & 1033.44 & -6.43 \\
\hline & PM3 & 3.142 & -0.123 & 0.562 & 12.638 & 620.13 & 1045.44 & -6.33 \\
\hline \multirow{2}{*}{ (E)-4 } & $\mathrm{AM} 1$ & 1.761 & -0.118 & 0.105 & 14.954 & 612.69 & 1041.26 & -5.92 \\
\hline & PM3 & 0.642 & -0.124 & 0.500 & 14.893 & 627.96 & 1061.31 & -5.91 \\
\hline \multirow{2}{*}{ (Z)-4 } & $\mathrm{AM} 1$ & 3.237 & -0.120 & 0.309 & 11.855 & 599.65 & 1023.35 & -6.28 \\
\hline & PM3 & 2.818 & -0.124 & 0.496 & 11.488 & 607.57 & 1034.30 & -6.17 \\
\hline
\end{tabular}

a) Computed as the maximum atomic distance in the molecule.

$$
\omega=\frac{\mu^{2}}{2 \eta}
$$

Table 9 presents the energy values of HOMO and LUMO orbitals, energy gap $(\Delta E)$ and molecular descriptors $(\chi, \eta$ and $\omega)$ calculated for azobenzene derivatives (1-4) at the level of semi-empirical Hamiltonians AM1 and PM3. The energetic values from Table 9 reveal that the energy gap $\left(\Delta E=\varepsilon_{\mathrm{LUMO}}-\varepsilon_{\mathrm{HOMO}}\right)$ of studied azobenzene derivatives (1-4) varies from $7.022 \mathrm{eV}$ to $7.860 \mathrm{eV}$. In most of the

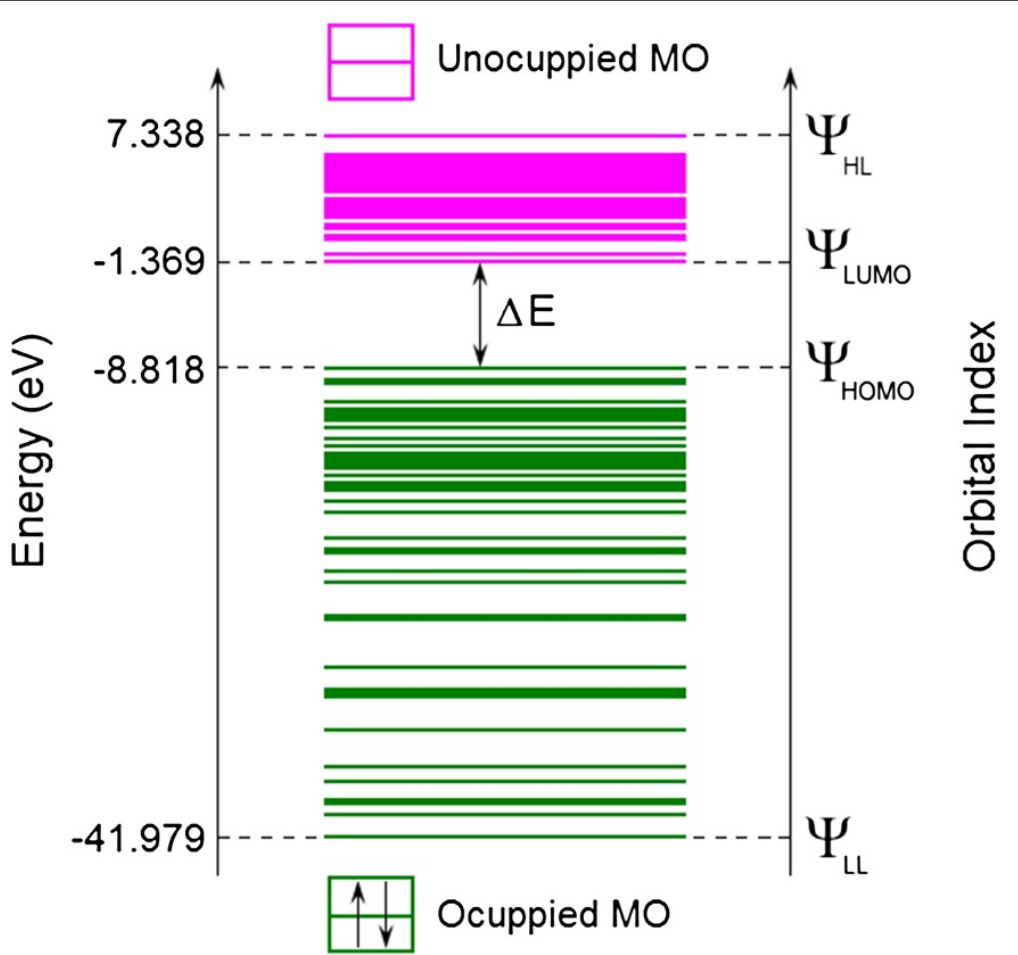

Figure 8 Energy spectrum of molecular orbitals computed by AM1 method for $(E)-1$ azobenzene derivative, in its ground state $\left(\mathrm{S}_{0}\right)$. 
Table 9 Energies of frontier MOs, the energy gap and molecular descriptors computed at the level of AM1 and PM3 Hamiltonians for (1-4)

\begin{tabular}{|c|c|c|c|c|c|c|c|}
\hline \multicolumn{2}{|c|}{ Compound } & \multirow{2}{*}{$\frac{\varepsilon_{\text {LUMO, }}(\mathrm{eV})}{-1.369}$} & \multirow{2}{*}{$\frac{\varepsilon_{\text {номо }}(\mathrm{eV})}{-8.818}$} & \multirow{2}{*}{$\frac{\Delta E,(\mathrm{eV})}{7.449}$} & \multirow{2}{*}{$\frac{X_{r}(\mathrm{eV})}{5.093}$} & \multirow{2}{*}{$\frac{\eta_{,}(\mathrm{eV})}{3.724}$} & \multirow{2}{*}{$\frac{\omega,(\mathrm{eV})}{3.483}$} \\
\hline (E) -1 & AM1 & & & & & & \\
\hline (ㄷ) 1 & PM3 & -1.443 & -8.927 & 7.484 & 5.185 & 3.742 & 3.592 \\
\hline \multirow{2}{*}{$(\mathrm{Z})-1$} & AM1 & -1.397 & -9.097 & 7.700 & 5.247 & 3.850 & 3.575 \\
\hline & PM3 & -1.344 & -9.138 & 7.794 & 5.241 & 3.897 & 3.524 \\
\hline \multirow{2}{*}{ (E)-2 } & AM1 & -1.536 & -8.558 & 7.022 & 5.047 & 3.511 & 3.627 \\
\hline & PM3 & -1.457 & -8.738 & 7.281 & 5.098 & 3.640 & 3.569 \\
\hline \multirow{2}{*}{ (Z)-2 } & AM1 & -1.534 & -8.834 & 7.300 & 5.184 & 3.650 & 3.681 \\
\hline & PM3 & -1.457 & -8.940 & 7.483 & 5.199 & 3.741 & 3.611 \\
\hline \multirow{2}{*}{ (E)-3 } & AM1 & -1.324 & -8.783 & 7.459 & 5.053 & 3.729 & 3.424 \\
\hline & PM3 & -1.436 & -9.001 & 7.565 & 5.218 & 3.782 & 3.600 \\
\hline \multirow{2}{*}{ (Z)-3 } & AM1 & -1.366 & -9.071 & 7.705 & 5.218 & 3.853 & 3.534 \\
\hline & PM3 & -1.363 & -9.134 & 7.771 & 5.248 & 3.886 & 3.545 \\
\hline \multirow{2}{*}{ (E)-4 } & AM1 & -1.355 & -8.884 & 7.529 & 5.120 & 3.765 & 3.481 \\
\hline & PM3 & -1.332 & -9.193 & 7.860 & 5.263 & 3.930 & 3.523 \\
\hline \multirow{2}{*}{ (Z)-4 } & AM1 & -1.365 & -9.136 & 7.771 & 5.250 & 3.885 & 3.548 \\
\hline & PM3 & -1.374 & -9.177 & 7.803 & 5.276 & 3.901 & 3.567 \\
\hline
\end{tabular}

cases, the calculated values of energy gap $(\Delta E)$, electronegativity $(\chi)$ and chemical hardness $(\eta)$ are slightly higher for $(Z)$ isomers than for $(E)$ isomers.

The plots of HOMO and LUMO molecular orbitals for the isomers (E)-1 and (Z)-1 are shown as an example in Figure 9. The negative phase of wave-function is illustrated with blue color, while the positive phase with green color. As one can see, for both isomers (E)-1 and (Z)-1 the HOMO lobes are spread mainly over aromatic rings and azo group. In contrast, the LUMO lobes are almost uniformly distributed over maleimide moiety. Similar distribution of frontier orbitals have been obtained and for the other compounds $2-4$.
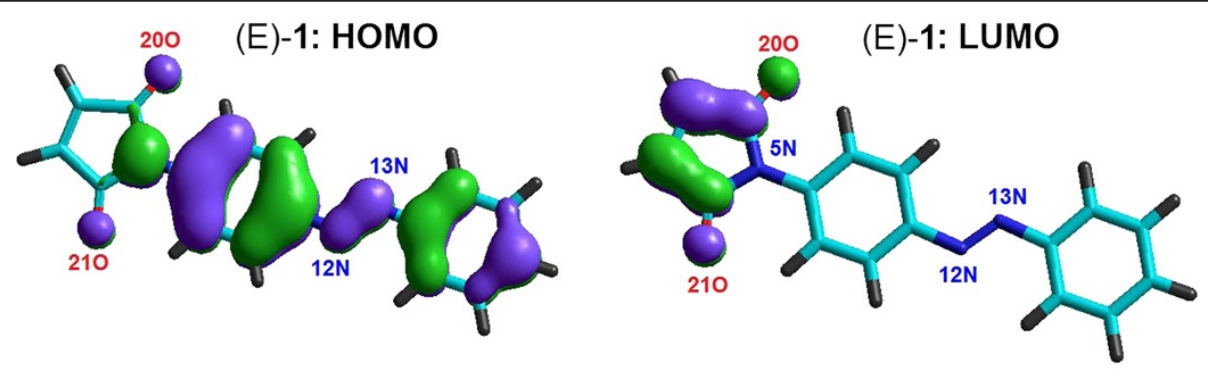

(Z)-1: HOMO
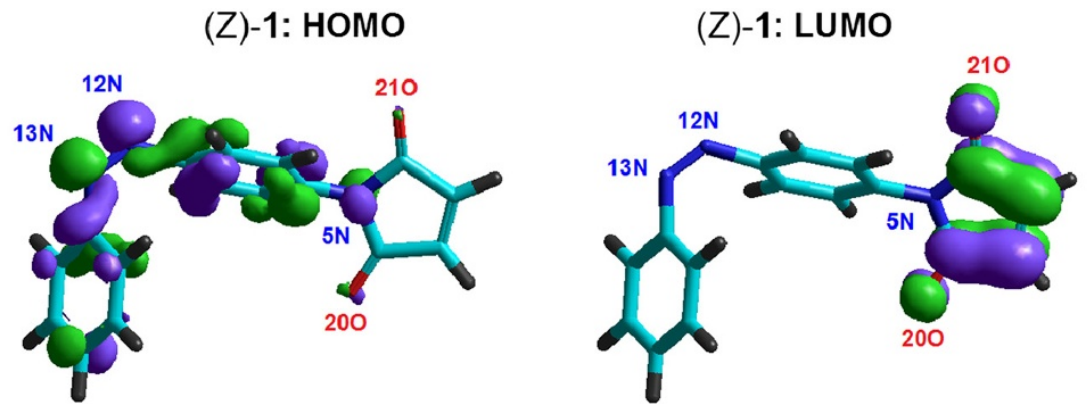

Figure 9 Frontier orbital plots (HOMO-LUMO) for optimized geometries of azobenzene derivative isomers (E)-1 and (Z)-1 computed at the level of PM3 method; partial atomic numbering. 


\section{Simulated electronic absorption spectra}

Electronic absorption spectra arise from transitions between electronic states of different quantum numbers induced by electromagnetic radiation with ultraviolet or visible (UV-vis) light (Grimme 2004). The organic molecules containing $\pi$-electrons and lone-pairs electrons (n-electrons) allow under UV-vis radiation $(>200 \mathrm{~nm})$ the electronic transitions of type $n \rightarrow \pi^{*}$ and $\pi \rightarrow \pi^{*}$. The intensities of the bands corresponding to $n \rightarrow \pi^{*}$ transitions are usually lower than those attributed for $\pi \rightarrow \pi^{*}$ transitions (Kazitzyna \& Kupletskaya 1971). In order to reveal electronic transitions, their energies and oscillator strengths, the theoretical absorption spectra play an important role (Mahadevan et al. 2012).

The singly-excited configuration interaction method (CI) at the level of semi-empirical Hamiltonians (AM1 and PM3) has been employed to calculate the theoretical absorption electronic spectra of the investigated azobenzene

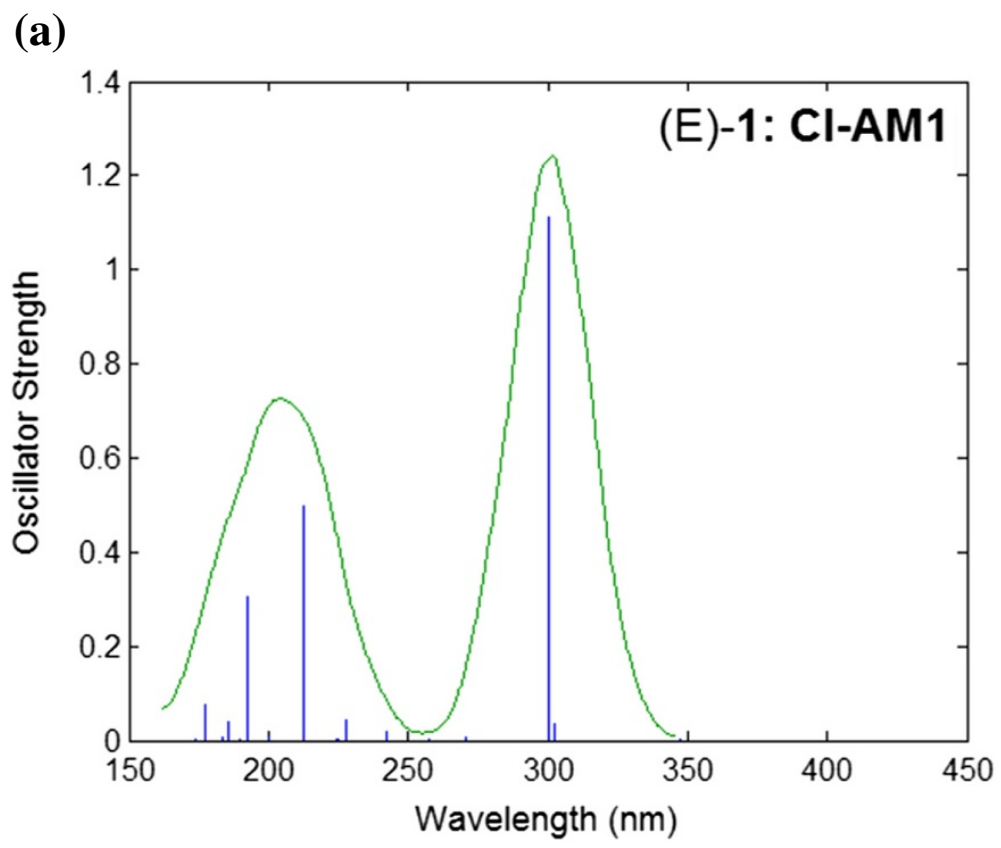

(b)

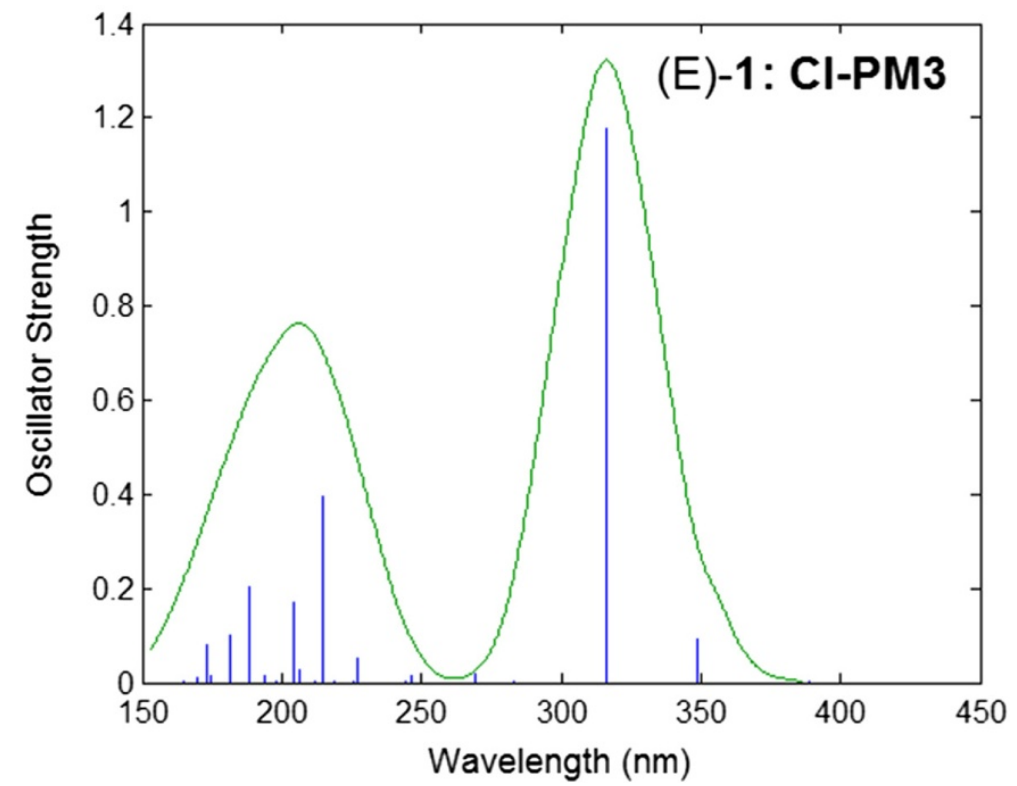

Figure 10 Theoretical UV-vis absorption spectra for (E)-1 azobenzene derivative: $\mathrm{Cl}-\mathrm{AM} 1$ (a) and $\mathrm{Cl}-\mathrm{PM} 3$ (b) computation results. 
derivatives (1-4). Note that, configuration interaction (CI) involves the excitation of a single electron from one of the occupied orbital to one of the unoccupied orbital. For calculation of electronic spectra based on CI-method the HyperChem program has been used. In this respect, the energy criterion has been selected by setting the maximum excitation energy at the level of $10 \mathrm{eV}$, which is larger than the HOMO-LUMO gap of studied molecules (1-4). The computation of theoretical electronic spectrum by HyperChem involves the performing of CI calculation in conjunction with single point energy calculation. To this end, a self-consistent-field calculation (SCF) is first performed to obtain the reference electronic configuration associated with the singlet ground state of the molecule. Afterwards, HyperChem generates a series of singly excited configurations, computes the Hamiltonian matrix elements between them, and then diagonalizes the matrix to get the spectrum of electronic states (HyperChem 2002). Note that, the solvent effect has not considered for simulation of electronic spectra.
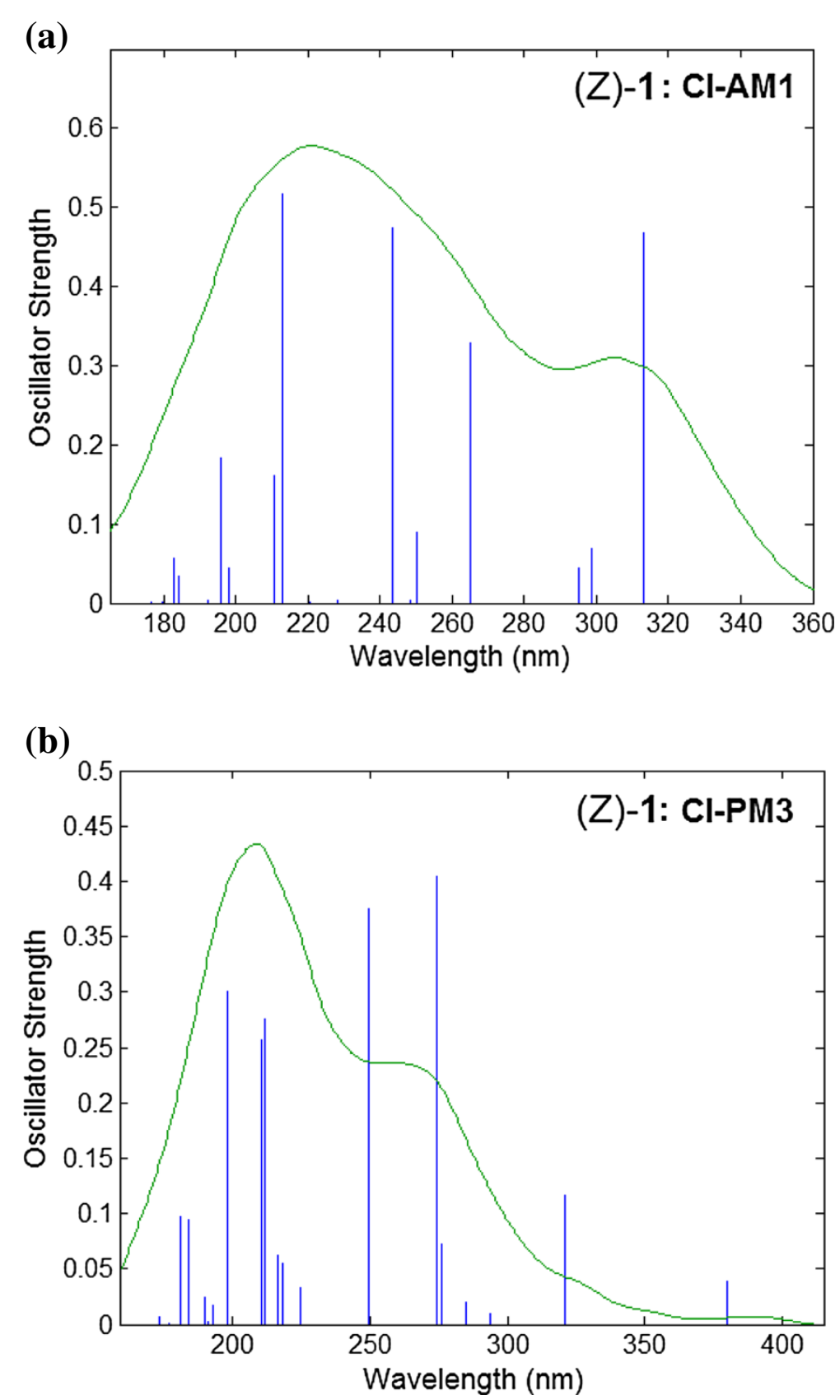

Figure 11 Theoretical UV-vis absorption spectra for (Z)-1 azobenzene derivative: $\mathrm{Cl}-\mathrm{AM} 1$ (a) and CI-PM3 (b) computation results. 
Figure 10 shows the theoretical UV-vis absorption spectra for (E)-1 isomer computed from a single point energy calculation at the level of semi-empirical Hamiltonians (AM1 and PM3) using singly-excited configuration interaction (CI). The simulated electronic absorption spectra are presented by plotting the transition energy given as wavelength versus their intensity given as oscillator strength $(f)$. Transitions in the spectra are represented as separate vertical blue lines (peaks) denoting the excited electronic states that are spectroscopically active. These transitions are mainly of type singlet (ground state)-tosinglet (excited state). Likewise, the plotted electronic spectra display the fitting line (green), which is formed by nonlinear fit, i.e. applying a Gaussian or Lorentzian distribution to each peak using a line width adjustable parameter (HyperChem 2002). As one can see from Figure 10a, the method CI-AM1 predicts for isomer (E)-1 the highest peak at $300.07 \mathrm{~nm}$ with oscillator strength (intensity) of $f=1.113$. This peak is assigned to the transition $\mathrm{HOMO} \rightarrow \mathrm{LUMO}_{+1}$. For the same isomer (E)-1, Figure 10b displays the electronic spectrum computed by CI-PM3 method. In this case, the highest peak appears at $316.11 \mathrm{~nm}$ with oscillator strength of $f=1.175$, being also assigned to the transition $\mathrm{HOMO} \rightarrow \mathrm{LUMO}_{+1}$.

Figure 11 shows the simulated electronic spectra for the isomer $(Z)-1$. By comparing the calculated electronic spectra of isomers (E)-1 (Figure 10) and (Z)-1 (Figure 11), one can see that the oscillator strengths are smaller in case of (Z)-1. The method CI-AM1 predicts for (Z)-1 a transition at $312.90 \mathrm{~nm}$ with oscillator strength of 0.467 (Figure 11a), being assigned to $\mathrm{HOMO} \rightarrow \mathrm{LUMO}_{+1}$.
Figure 11b illustrates that according to CI-PM3 method, the highest peak appears at $274.51 \mathrm{~nm}$ with an intensity of $f=0.405$ attributed to the transition $\mathrm{HOMO} \rightarrow \mathrm{LUMO}_{+1}$.

For the compounds (1-4), the calculated wavelengths higher than $300 \mathrm{~nm}$ are of interest, since the experimental studies revealed the absorption bands of the $\pi \rightarrow \pi^{*}$ or $\mathrm{n} \rightarrow \pi^{*}$ transitions in this domain. In this respect, Table 10 presents the theoretical wavelengths $(\lambda)$ with values higher than $300 \mathrm{~nm}$, their oscillator strengths $(f)$ and excitation energies $\left(E_{\lambda}\right)$ as well as the corresponding spectral assignments calculated for (E) / (Z) isomers of compounds (1-4). As can be observed from the data reported in Table 10, for this spectral domain $(\lambda>300 \mathrm{~nm})$ the oscillator strengths are higher for (E) isomers comparing with $(Z)$ ones. Table 11 summarizes the maximum absorption wavelengths $\left(\lambda_{\max }\right)$ determined experimentally from UV-vis absorption spectra of studied compounds (1-4) in various solvents. Thus, according to the data presented in Table 11, the absorption bands have been observed for (1-4) in the spectral domain $\lambda>300 \mathrm{~nm}$, i.e. in the range $327-470 \mathrm{~nm}$. The differences between the theoretical values of absorption maxima and the experimental spectral data can arise from the fact that the calculations were carried out for gas phase, while the experimental values were obtained in solvent at room temperature.

\section{Spin densities}

Intersystem crossing from the excited singlet state to an intermediate triplet state may occur at some point where the potential energy surfaces of the singlet and triplet

Table 10 Theoretical wavelengths and oscillator strengths computed by $\mathrm{Cl}-\mathrm{AM} 1$ and $\mathrm{Cl}-\mathrm{PM} 3$ methods for (1-4)

\begin{tabular}{|c|c|c|c|c|c|}
\hline \multicolumn{2}{|c|}{ Compound } & \multirow{2}{*}{$\begin{array}{l}\lambda(\mathrm{nm}) \\
300.07\end{array}$} & \multirow{2}{*}{$\begin{array}{c}f \\
1.113\end{array}$} & \multirow{2}{*}{$\begin{array}{c}E_{\lambda}(\mathrm{eV}) \\
4.132\end{array}$} & \multirow{2}{*}{$\begin{array}{c}\text { Assignment (Transition): } \\
\text { Occ. MO } \rightarrow \text { Unocc. MO } \\
\mathrm{HOMO} \rightarrow \mathrm{LUMO}_{+1}\end{array}$} \\
\hline$(\mathrm{E})-1$ & AM1 & & & & \\
\hline & PM3 & 316.11 & 1.175 & 3.922 & $\mathrm{HOMO} \rightarrow \mathrm{LUMO}_{+1}$ \\
\hline \multirow[t]{2}{*}{ (Z)-1 } & AM1 & 312.90 & 0.467 & 3.962 & $\mathrm{HOMO} \rightarrow \mathrm{LUMO}_{+1}$ \\
\hline & PM3 & 320.87 & 0.116 & 3.864 & $\mathrm{HOMO} \rightarrow \mathrm{LUMO} \mathrm{HOMO}_{-1} \rightarrow \mathrm{LUMO}$ \\
\hline \multirow[t]{2}{*}{ (E)-2 } & AM1 & 315.55 & 1.507 & 3.929 & $\mathrm{HOMO} \rightarrow \mathrm{LUMO}_{+1}$ \\
\hline & PM3 & 321.69 & 1.274 & 3.854 & $\mathrm{HOMO} \rightarrow \mathrm{LUMO}_{+1}$ \\
\hline \multirow[t]{2}{*}{ (Z)-2 } & AM1 & 314.17 & 0.770 & 3.946 & $\mathrm{HOMO} \rightarrow \mathrm{LUMO}_{+1} ; \mathrm{HOMO} \rightarrow \mathrm{LUMO}_{+2}$ \\
\hline & PM3 & 314.71 & 0.110 & 3.940 & $\mathrm{HOMO}_{-2} \rightarrow \mathrm{LUMO} \mathrm{HOMO}_{-7} \rightarrow$ LUMO \\
\hline \multirow[t]{2}{*}{ (E)-3 } & AM1 & 366.98 & 0.407 & 3.379 & $\mathrm{HOMO} \rightarrow \mathrm{LUMO}_{+2} ; \mathrm{HOMO}_{-4} \rightarrow \mathrm{LUMO}_{+2}$ \\
\hline & PM3 & 319.86 & 0.641 & 3.876 & $\mathrm{HOMO} \rightarrow \mathrm{LUMO}_{+2}$ \\
\hline \multirow[t]{2}{*}{ (Z)-3 } & AM1 & 321.84 & 0.234 & 3.852 & $\mathrm{HOMO} \rightarrow \mathrm{LUMO}_{+2}$ \\
\hline & PM3 & 315.85 & 0.085 & 3.925 & $\mathrm{HOMO}_{-1} \rightarrow \mathrm{LUMO} \mathrm{HOMO}_{-6} \rightarrow$ LUMO \\
\hline \multirow[t]{2}{*}{ (E)-4 } & AM1 & 360.24 & 0.281 & 3.442 & $\mathrm{HOMO} \rightarrow \mathrm{LUMO}_{+2} ; \mathrm{HOMO}_{-4} \rightarrow \mathrm{LUMO}_{+2}$ \\
\hline & PM3 & 300.95 & 0.339 & 4.120 & $\mathrm{HOMO} \rightarrow \mathrm{LUMO}_{+2}$ \\
\hline \multirow[t]{2}{*}{ (Z)-4 } & AM1 & 320.67 & 0.186 & 3.866 & $\mathrm{HOMO} \rightarrow \mathrm{LUMO}_{+2}$ \\
\hline & PM3 & 317.78 & 0.089 & 3.902 & $\mathrm{HOMO}_{-1} \rightarrow \mathrm{LUMO} \mathrm{HOMO}_{-6} \rightarrow \mathrm{LUMO}$ \\
\hline
\end{tabular}


Table 11 Experimental wavelengths determined from UV-vis absorption spectra

\begin{tabular}{ccc}
\hline Compound & Solvent & $\lambda_{\max }^{\text {exper }}(\mathbf{n m})$ \\
\hline 1 & Chloroform & $327 ; 470$ \\
2 & Chloroform & $344 ; 441$ \\
& Dioxane & 356 \\
& Dichloromethane & 352 \\
& Dimethylformamide & 358 \\
3 & Dimethyl sulfoxide & 362 \\
& Tetrahydrofuran & 344 \\
4 & Toluene & 345 \\
& Dimethylformamide & $345.5 ; 442$ \\
& Dichloromethane & 344 \\
& Dimethylformamide & 342 \\
\hline
\end{tabular}

states intersect at a common geometry of the studied molecule (Morley et al. 2004). Our computational results based on semi-empirical models (AM1 and PM3) indicated that for studied azobenezene derivatives (1-4), the first triplet state $\left(\mathrm{T}_{1}\right)$ lies around 8 to $43 \mathrm{kcal} / \mathrm{mol}$ above the ground state $\left(\mathrm{S}_{0}\right)$. The two unpaired electrons in the triplet state may not be distributed uniformly throughout the molecular frame but rather localized at certain atomic centers (Morley et al. 2004). A visual illustration of the spin densities of the two azobenzene derivatives, (E)-1 and (E)-3, in their first excited triplet state $\left(T_{1}\right)$ is presented in Figure 12. Note that, Figure 12 shows the optimized geometries for $\mathrm{T}_{1}$ excited state, computed by AM1 method using unrestricted Hartree-Fock (UHF) spin pairing level. As one can see, AM1 computation results indicated that, for both compounds (E)-1 and (E)-3, the electron spin density in the first excited triplet state is concentrated at azo nitrogen atoms (Figure 12). In

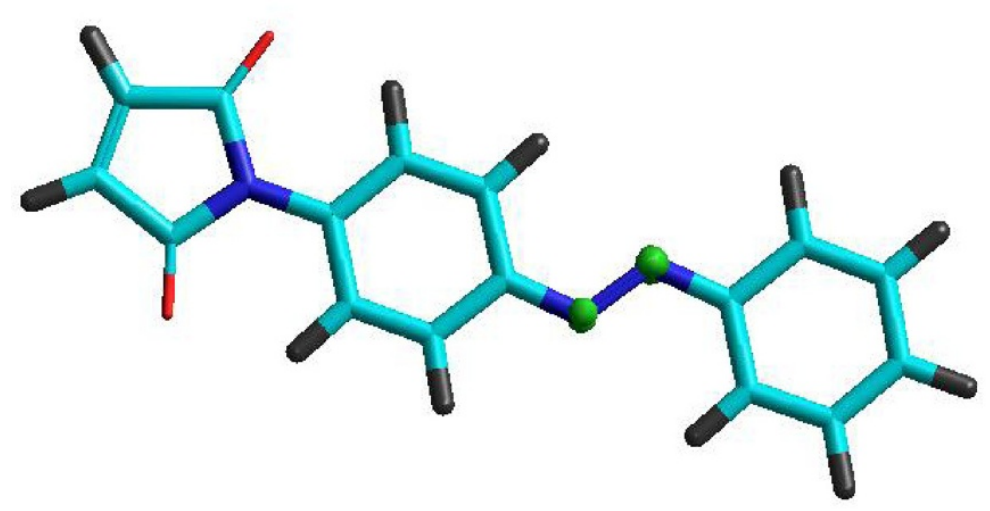

a)

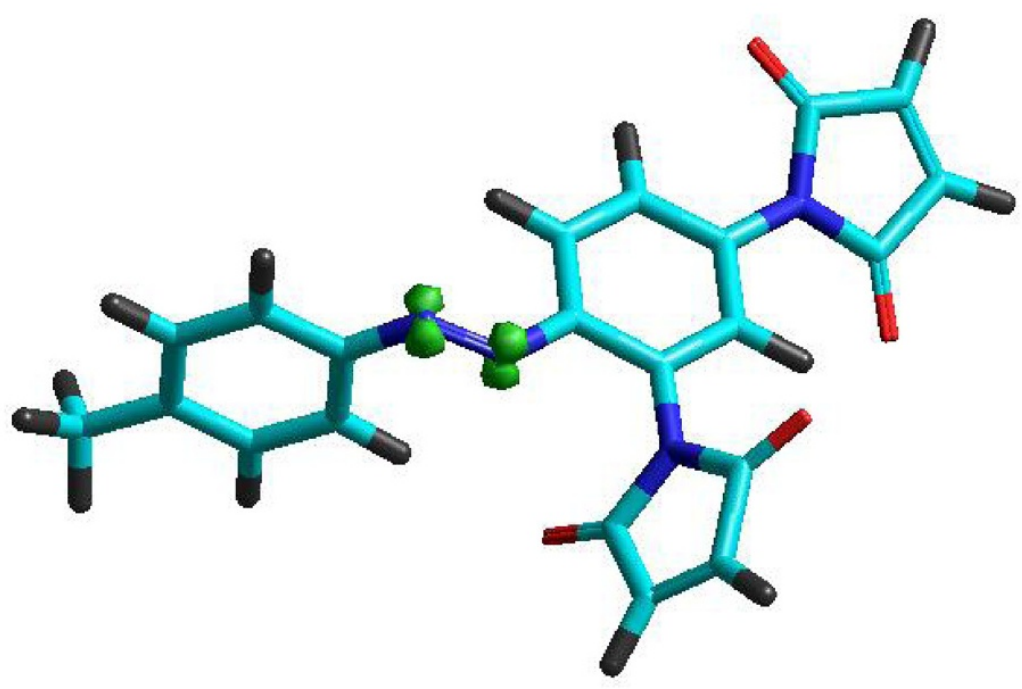

b)

Figure 12 Structure and spin density distribution (shown as green spheres) of the first excited triplet state $\left(T_{1}\right)$ for a) $(E)-1$ and $\left.b\right)(E)-3$ computed by AM1 method. 
contrast, additional calculation at PM3 level (for both (E)1 and (E)-3) has revealed that the electron spin density in state $T_{1}$ is localized at nitrogen atom from maleimide group. For the compound (E)-2, both AM1 and PM3 methods have disclosed the spin density concentrated at azo nitrogen atoms. Morley and co-workers (Morley et al. 2004) suggested that a greater localization of spin density at the reactive azo nitrogen atoms in the excited triplet state may be correlated with the lower photochemical stability of some azobenzene derivatives. The experimental results showed that azo derivatives 2 and 3 provide high yields of the $(\mathrm{Z})$ isomers at irradiation with UV light (365 nm) (Airinei et al. 2011b).

\section{Conclusions}

Quantum mechanics calculations were performed to investigate the structure and stability of $(\mathrm{E}) /(\mathrm{Z})$ isomers of azobenzene derivatives 1-4 containing maleimide groups. The calculations at the theoretical level of PM3, MNDO, RHF/6-31+G(d,p) and B3LYP/6-31+G(d,p) indicated that (E) isomers of $1-4$ are the most stable.

The available X-ray-structure-analysis data for the compound (E)-1, (E)-1-(4-(phenyldiazenyl)phenyl)-1Hpyrrole-2,5-dione, were used to validate the modeling geometries computed at the theoretical levels AM1, PM3, RHF/6-31+G(d,p) and B3LYP/6-31+G(d,p). The results revealed that ab-initio calculations at $R H F / 6-31+G(d, p)$ level yield the most accurate prediction on (E)-1 structure, giving a deviation error from crystallographic data of about $5.00 \%$ for bond lengths and $0.97 \%$ for valence angles.

For all azobenzenes studied in this paper, the applied semi-empirical methods (AM1 and PM3) have indicated that the calculated net atomic charges of azo nitrogen atoms $(\mathrm{N}=\mathrm{N})$ are smaller in case of $(\mathrm{E})$ isomers comparing with $(\mathrm{Z})$ isomers. The computed values of the energy gap of studied azobenzene derivatives (1-4), in their ground state, varied from $7.022 \mathrm{eV}$ to $7.860 \mathrm{eV}$. In most of the cases, the calculated values of energy gap, electronegativity and chemical hardness were slightly higher for $(Z)$ isomers than for (E) isomers. The plotting of frontier molecular orbitals (HOMO and LUMO) for 1-4 showed that the HOMO levels were spread mainly over aromatic rings and azo group. In contrast, the LUMO levels were almost uniformly distributed over maleimide moiety. The theoretical electronic spectra of azobenzene derivatives 1-4 were computed by configuration-interaction method $(\mathrm{CI})$ at the level of semi-empirical Hamiltonians, revealing the transitions and the corresponding oscillator strengths.

\section{Nomenclature}

AM1 Austin Method 1 (semi-empirical model)

$A R E$ average relative error

B3LYP Becke exchange and Lee-Yang-Parr correlation functionals
CI configuration interaction

DFT density functional theory

$D M$ dipole moment

(E) isomer notation (Entgegen): higher-priority substituents are on the opposite side

$E$ binding energy

$E A$ electron affinity

$E_{\lambda}$ excitation energy

$E_{H}$ hydration energy

$E_{r e l}$ relative strain energy

$\triangle E$ energy gap

ESP electrostatic potential

HOMO highest occupied molecular orbital

$f$ oscillator strength

$H$ heat of formation

IP ionization potential

LUMO lowest unoccupied molecular orbital

MNDO Modified Neglect of the Diatomic Overlap

(semi-empirical model)

MO molecular orbital

$n$ lone pairs electrons

$N$ number of data (available experimental data)

OMO occupied molecular orbital

PM3 Parameterization Method 3 (semi-empirical model)

QM quantum mechanics

QSAR quantitative structure-activity relationship

RHF restricted Hartree-Fock basis

$R M S D$ root-mean-square error deviation

SCF self-consistent field method

$\mathrm{S}_{0}$ ground state

$\mathrm{T}_{1}$ first excited triplet state

UHF unrestricted Hartree-Fock basis

UMO unoccupied (virtual) molecular orbital

$X$ structural parameter

(Z) isomer notation (Zusammen): higher-priority substituents are on the same side

\section{Greeks letters}

$X$ electronegativity

$\varepsilon$ energy (eigenvalue)

$\eta$ chemical hardness

$\lambda$ wavelength

$\mu$ chemical potential

$\pi$ bonding molecular orbital ( $\pi$-symmetry)

$\pi^{*}$ antibonding molecular orbital ( $\pi$-symmetry)

$\omega$ electrophilicity index

$\Psi$ wave-function (orbital)

\section{Subscripts and superscripts}

calc calculated (theoretical) value

exp experimental value

$i$ positive integer number (iteration index)

$j$ positive integer number (iteration index)

max maximum 


\section{Competing interests}

The authors declare that they have no competing interests.

\section{Authors' contributions}

CC carried out the computational simulations. CC, AA, NF analyzed the data and wrote the manuscript. AA and NF designed and performed the experiments related to the UV-Vis absorption spectra. All authors read and approved the final manuscript.

\section{Acknowledgement}

The authors gratefully acknowledge the financial support of this work from European Union's Framework Programme for Research via Project STREAM (grant agreement no. 264115, call FP7-REGPOT-2010-1).

\section{Received: 26 September 2013 Accepted: 1 October 2013}

Published: 31 October 2013

\section{References}

(2002) HyperChem release 7 for windows (user guide), printed in USA. Hypercube, Inc

Airinei A, Rusu E, Barboiu V (2010) Responsive behavior of 4-(N-maleimide) azobenzene in polymers with aromatic main chain and side chain linked units. J Braz Chem Soc 21:489-495

Airinei A, Homocianu M, Fifere N, Gaina C, Gaina V (2011a) Optical properties of some bismaleimide derivatives. Optoelectr Adv Mater-Rapid Commun 5:655-660

Airinei A, Fifere N, Homocianu M, Gaina C, Gaina V, Simionescu BC (2011b) Optical properties of some new azo photoisomerizable bismaleimide derivatives. Int J Mol Sci 12:6176-6193

Angiolini L, Benelli T, Giorgini L, Golemme A, Salatelli E, Termine R (2011) Side-chain multifunctional photoresponsive polymeric materials. In: Predeep P (ed) Optoelectronics - materials and techniques. InTech, Rijeka, Croatia, pp 187-210

Bouas-Laurent H, Durr H (2001) Organic photochromism. Pure Appl Chem 73:639-665

Delaire JA, Nakatani K (2000) Linear and nonlinear optical properties of photochromic molecules and materials. Chem Rev 100:1817-1846

Diau EWG (2004) A new trans-to-cis photoisomerization mechanism of azobenzene on the S1 (n$\left.\pi^{*}\right)$ surface. J Phys Chem A 108:950-956

Ebead YH (2011) Spectrophotometric investigations and computational calculations of prototropic tautomerism and acid-base properties of some new azo dyes. Dyes Pigm 92:705-713

Fayet G, Jacquemin D, Wathelet V, Perpete EA, Rotureanu P, Adano C (2010) Excited-state properties from ground-state DFT descriptors: a QSPR approach for dyes. J Mol Graphics Modelling 28:465-471

Grimme S (2004) Calculation of the electronic spectra of large molecules. In: Lipkowitz KB, Larter R, Cundari TR (eds) Reviews in computational chemistry. Wiley, Inc, New-York, Vol. 20: 153-218

Hamelmann F, Heinzmann U, Siemeling U, Bretthauer F, Vor de Bruggen J (2004) Light-stimulated switching of azobenzene-containing self-assembled monolayers. Appl Surf Sci 222:1-5

Hulubei C, Buiceac D (2005) Liquid crystal maleimide monomers. Bul Inst Pol lasi, Chim Ing Chim 51(3/4):59-65

Hurjui I, Ivan LM, Dorohoi DO (2013) Solvent influence on the electronic absorption spectra (EAS) of 1,6-diphenyl-1,3,5-hexatriene (DPH). Spectrochim Acta, Part A 102:219-225

Ishow E, Lebon B, He YN, Wang XG, Bouteiller L, Galmiche L, Nakatani K (2006) Structural and photoisomerization cross studies of polar photochromic monomeric glasses forming surface relief gratings. Chem Mater 18:1261-1267

Jesintha John C, Xavier TS, Amalanathan M, Hubert Joe I, Rastogi VK (2012) Analysis of vibrational spectra and nonlinear optical properties of organic molecule L-alaninium formate. Spectrochim Acta, Part A 86:174-180

Kay ER, Leigh DA, Zerbetto F (2007) Synthetic molecular motors and mechanical machines. Angew Chem, Int Ed 46:72-191

Kazitzyna LA, Kupletskaya NB (1971) Application of UV-, IR-, and NMR- spectroscopy in organic chemistry (in Russian). Vysshaya Shkola (Publisher), Moscow

Kumar GS, Neckers DC (1989) Photochemistry of azobenzene-containing polymers. Chem Rev 89:1915-1925

Kurita N, Ikegami T, Ishikawa Y (2002) Ab initio study of the minimum-energy structure of trans-azobenzene. Chem Phys Lett 360:349-354
Luftor M, Hedge G, Kumar S, Tschierske C, Chigrinov VG (2009) Synthesis and characterization of bent-shaped azobenzene monomers: guest-host effects in liquid crystals with azo dyes for optical image storage devices. Opt Mater 32:176-183

Mahadevan D, Periandy S, Karabacak M, Ramalingam S, Puviarasan N (2012) Spectroscopic (FT-IR, FT-raman and UV-Vis) investigation and frontier molecular orbitals analysis on 3-methyl-2-nitrophenol using hybrid computational calculations. Spectrochim Acta, Part A 86:139-151

Matczyszyn K, Bactkiewicz S, Sahraoui B (2003) A new holographic system: liquid crystal doped with photochromic molecules. Opt Mater 21:301-305

Matsuura A, Sato H, Sotoyama W, Takahashi A, Sakurai M (2008) AM1, PM3, and PM5 calculations of the absorption maxima of basic organic dyes. J Mol Structure: THEOCHEM 860:119-127

Merino E, Ribagorda M (2012) Control over molecular motion using the cis-trans photoisomerization of the azo group. Beilstein J Org Chem 8:1071-1090

Morley JO, Guy OJ, Charlton MH (2004) Molecular modeling studies on the photochemical stability of azo dyes. J Phys Chem A 108:10542-10550

Natansohn A, Rochon P (2002) Photoinduced motions in azo-containing polymers. Chem Rev 102:4139-4175

Ramachandran Kl, Deepa G, Namboori K (2008) Computational chemistry and molecular modeling: principles and applications. Springer-Verlag, Berlin, Heidelberg

Rau H (1990a) Azo compounds. In: Durr H, Bouas-Laurent H (eds) Photochromism, molecules and systems. Elsevier, Amsterdam, pp 165-192

Rau H (1990b) Photoisomerization of azobenzenes. In: Rabek JF (ed) Photochemistry and photophysics. CRC Press, Boca Raton, FL, USA, vol. 2: 119-141

Rusu E, Shova S, Rusu G (2011) 1-[(E)-4-(Phenyldiazenyl)phenyl]-3-pyrroline-2,5dione. Acta Crystallog E67:02333

Satzger H, Spörlein S, Root C, Wachtveitl J, Zinth W, Gilch P (2003) Fluorescence spectra of trans- and cis-azobenzene - emission from the Franck-Condon state. Chem Phys Lett 372:216-223

Schultz T, Quenneville J, Levine B, Toniolo A, Martinez TJ, Lochbrumer S, Schmitt M, Shaffer JP, Zgierski MZ, Stolow A (2003) Mechanism and dynamics of azobenzene photoisomerization. J Am Chem Soc 125:8098-8099

Shaabani A, Zahedi M (2000) Semiempirical molecular orbital calculation of azobenzene: stability study of isomers and mechanism of E/Z isomerization. J Mol Structure: THEOCHEM 506:257-261

Wang G, Zhang J (2012) Photoresponsive molecular switches for biotechnology. J Photochem Photobiol C: Photochem Rev 13:299-309

Yager KG, Barett CJ (2006) Novel photoswitching using azobenzene functional materials. J Photochem Photobiol A Chem 182:250-261

\section{doi:10.1186/2193-1801-2-586}

Cite this article as: Cojocaru et al:: Molecular structure and modeling studies of azobenzene derivatives containing maleimide groups. SpringerPlus 2013 2:586.

\section{Submit your manuscript to a SpringerOpen ${ }^{\circ}$ journal and benefit from:}

- Convenient online submission

- Rigorous peer review

- Immediate publication on acceptance

- Open access: articles freely available online

- High visibility within the field

- Retaining the copyright to your article

Submit your next manuscript at $>$ springeropen.com 